Portland State University

PDXScholar

Civil and Environmental Engineering Master's

Project Reports

Summer 2019

\title{
Travel Behaviors of Persons with Intellectual and Developmental Disabilities
}

Joseph C. Totten

Portland State University

Follow this and additional works at: https://pdxscholar.library.pdx.edu/cengin_gradprojects

Part of the Civil and Environmental Engineering Commons

Let us know how access to this document benefits you.

\section{Recommended Citation}

Totten, Joseph C., "Travel Behaviors of Persons with Intellectual and Developmental Disabilities" (2019). Civil and Environmental Engineering Master's Project Reports. 45.

https://doi.org/10.15760/CCEMP.45

This Project is brought to you for free and open access. It has been accepted for inclusion in Civil and Environmental Engineering Master's Project Reports by an authorized administrator of PDXScholar. Please contact us if we can make this document more accessible: pdxscholar@pdx.edu. 
Travel Behaviors of Persons with Intellectual and Developmental Disabilities

BY

Joseph Totten

A research project report submitted in partial fulfillment

of the requirement for the degree of

\section{MASTER OF SCIENCE \\ IN \\ CIVIL AND ENVIRONMENTAL ENGINEERING}

Project Advisor:

Chris Monsere, $\mathrm{PhD}$

Portland State University

(C)2019 


\section{ACKNOWLEDGMENTS}

The author would like to thank organizations who distributed the survey to their membership including the Down Syndrome Association of Minnesota, the Autism Society of Minnesota, the Autism Society of Oregon, the A.R.C. of Oregon, the A.R.C. of Minnesota and the Highland Friendship Club. Additional thanks to Chris Monsere for advising this project, and to other assorted professors at Portland State University for their assistance in small portions of the project. Special thanks to Dan Reid for helping connect and distribute the survey throughout Minnesota.

Other thanks to my friends from Portland State's transportation engineering program, friends from the Multnomah Athletic Club and friends from the Oregon Department of Transportation for keeping me on schedule and working towards this reports completion. Thanks to the Carroll family and the Wilson-Sommerville family for their support in Portland. Thank you to my parents for their continual emotional support and encouraging me to expand the survey to Minnesota.

Final special thanks to my brothers Ozzie and Dave for letting me type and edit this report during the first few hours of their grooms' dinner. 


\begin{abstract}
People with intellectual and developmental disabilities live different lives than the general population. Often prohibited from driving, persons with intellectual disabilities cite transportation as top concern, limiting their independence and freedom to live, work or recreate where and when they choose. Improving services for persons with developmental disabilities requires that engineers and planners understand how persons with intellectual disabilities travel, and what types of transportation are available to them. This report hopes to identify the availability of transportation options to persons with developmental disabilities such that planners, engineers and advocates can determine how altering the transportation system might affect persons' with intellectual disabilities access to jobs, housing and services. Understanding the challenges inherent in various forms of transportation can help advocates prioritize the barriers to access, and which should be addressed immediately, and which need further discussion and research before a plan can be implemented.
\end{abstract}

This paper gathered data through an online survey of persons with intellectual and developmental disabilities, through advocacy organizations. The survey asked how often trips were made for various purposes, what modes were used to reach destinations, the level of concern for various modes and concerns, the level of independence and transportation skills, and how improved infrastructure might alter the independence of persons with developmental disabilities.

The results showed that persons with intellectual disabilities had more options to travel to daily tasks such as working or day programs, and that paratransit services were not utilized in any widespread manner except for these daily trips. For less frequent trips, persons with developmental disabilities are reliant on caregivers to provide transportation. The top concern for walking and cycling was traffic-safety, for fixed-route transit service it was being alone and for paratransit service it was the speed of the service. Finally, survey respondents reported that better nonmotorized infrastructure would increase their independence.

These results should be used to address the concerns in today's transportation system for persons with developmental disabilities, and by creating a basic understanding for researchers, advocates and decisionmakers when designing future research or changes to the current transportation system. 


\section{TABLE OF CONTENTS}

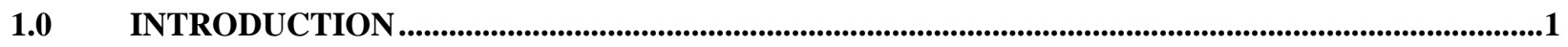

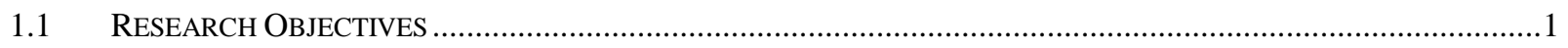

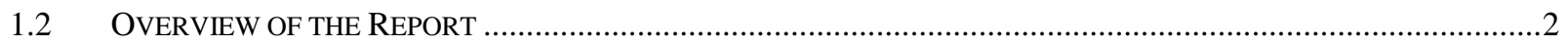

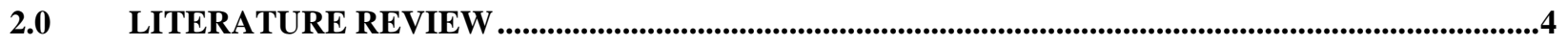

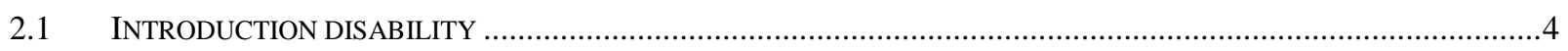

2.2 CULTURAL REPRESENTATIONS OF PEOPLE WITH DiSABILITIES ..........................................................

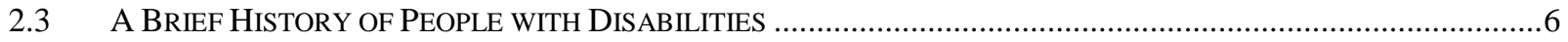

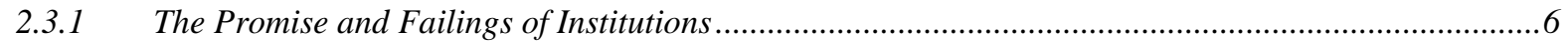

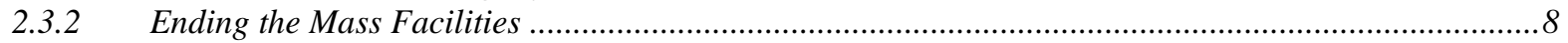

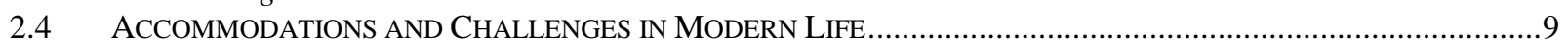

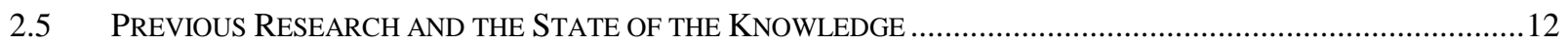

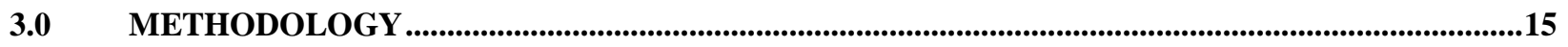

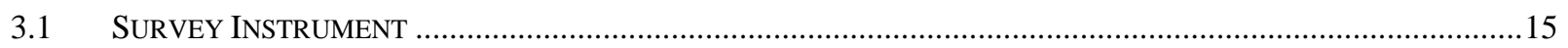

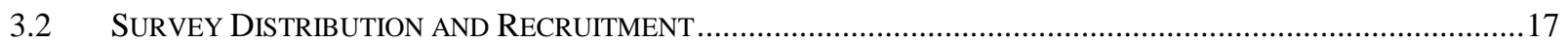

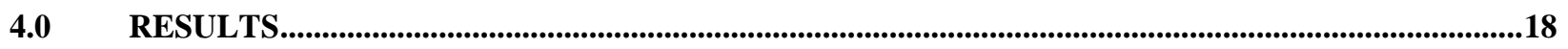

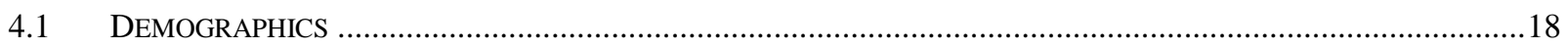

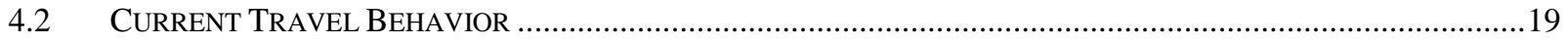

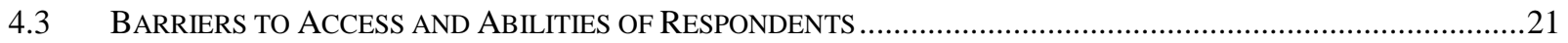

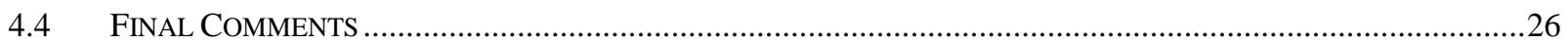

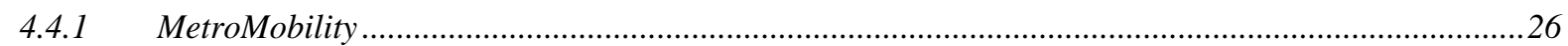

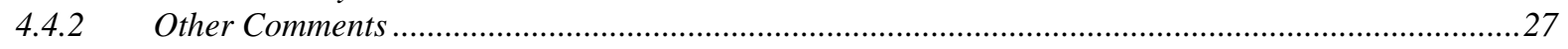

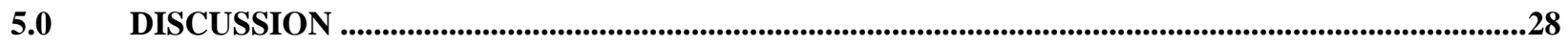

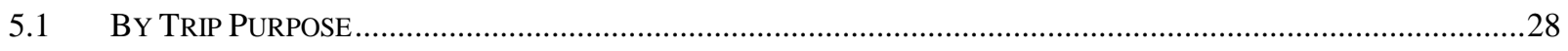

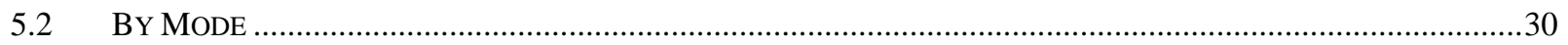

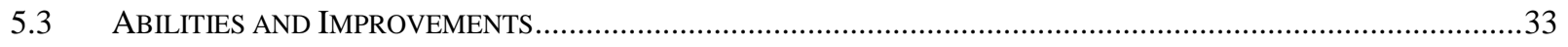

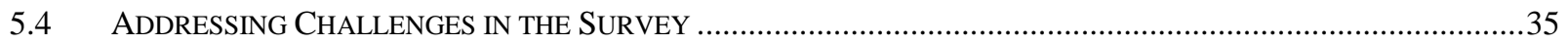

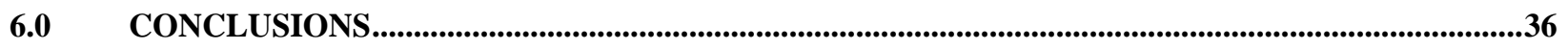

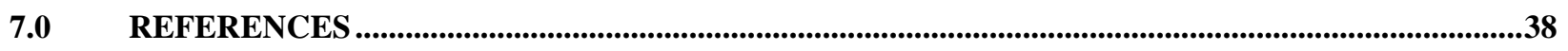

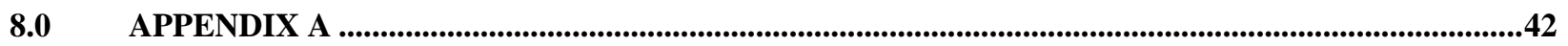

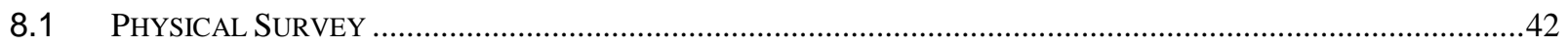




\section{LIST OF TABLES}

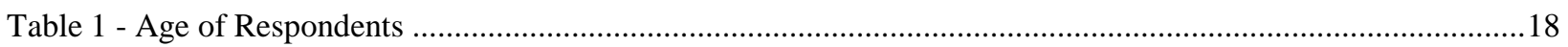

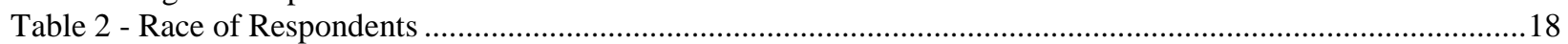

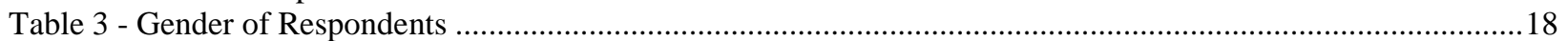

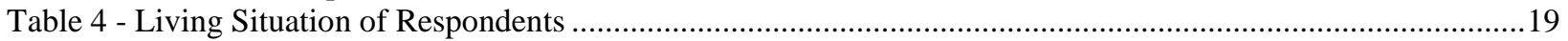

Table 5 - Annual Household Income of Respondents ......................................................................................19

Table 6 - Independence, Choice and Map Reading Ability ................................................................................25 


\section{LIST OF FIGURES}

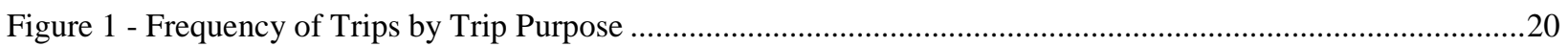

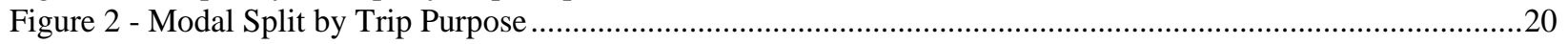

Figure 3 - Respondents' Dependence on Mode by Trip Purpose ......................................................................21

Figure 4 - Concerns about Walking ....................................................................................................22

Figure 5 - Concerns about Walking (Only Respondents Who Walk for Transportation) ...................................23

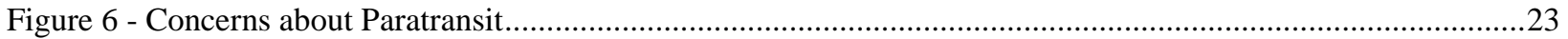

Figure 7 - Concerns about Fixed-Route Transit Service ...............................................................................24

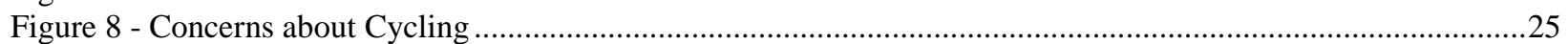

Figure 9 - Enjoyment of and Perceived Independence Gain from Non-Motorized Transportation ..........................26 


\subsection{INTRODUCTION}

Persons with intellectual and developmental disabilities are often unable to travel when and how they choose, largely due to being excluded from obtaining driving privileges. As the United States' built environments are organized primarily with large distances between land uses and activities, these restrictions on the independence of travel guarantee that persons with developmental disabilities are excluded from living independent lives and choosing the activities they wish to participate in. This exclusion does not only apply to provided services and social activities but also to work, trainings, running errands, shopping and other aspects of daily life. While new funds and/or organizations may increase the opportunities available for persons with intellectual disabilities, these new opportunities may not be available due to transportation barriers in accessing the transportation needed to leverage opportunities. The barrier of transportation may even exclude persons with developmental disabilities today. This study aims not to collect the personal stories and anecdotes of persons with intellectual disabilities, but to collect the information required to make these experiences generalizable. To do so this study must determine the following; the travel behavior of persons with intellectual disabilities, the concerns of travel for persons with disabilities and which improvements or interventions would most help increase the transportation independence of persons with developmental disabilities. These questions were addressed through an online survey which was distributed by partner organizations.

\subsection{Research Objectives}

This project intends to determine the general travel behavior of persons with intellectual disabilities, barriers and concerns inherent in modes available to persons with developmental disabilities and to determine the most productive future research and treatments to make improvements in the lives of persons with intellectual and developmental disabilities. This project collected its data by utilizing a survey of persons with intellectual disabilities and was distributed through partner organizations which specialize in supporting and advocating for persons with intellectual and developmental disabilities. Determining the existing travel behavior of persons with intellectual disabilities will be a base of data to evaluate how future changes in service may affect or address the travel demands of individuals with developmental disabilities. Determining the general barriers to various transportation modes for persons with developmental disabilities 
will allow for advocates and decisionmakers to target barriers more effectively and prioritize addressing the largest barriers to access. Determining the need and desire for specific interventions is needed to begin to make progress on eliminating the barriers to access, the final portion of this study addresses the need for select interventions.

\subsection{Overview of the Report}

This report will cover the basis of disability studies as it relates to the travel behavior of persons with developmental and intellectual disabilities, the previous work discussing transportation of persons with intellectual and developmental disabilities, the survey created for collecting the data, the results of the survey and what they indicate.

Persons with intellectual and developmental disabilities have suffered from a history of society's underfunding of services and apathy to their existence. This can be seen throughout history, but also in the cultural representations and interpretations of persons with disabilities. The representation of persons with disabilities in western culture largely ignores, if not erases the inner lives and emotions of persons with disabilities. Addressing the longstanding apathy to the very existence of persons with disabilities is required to make progress on providing effective services and opportunities for persons with disabilities, and without understanding the forms this apathy has taken will doom all noble attempts to improve conditions for persons with intellectual disabilities to reductions beyond what could remain effective.

There has been previous work discussing persons with intellectual and developmental disabilities and their travel behavior and barriers. These works are present throughout disability studies with guides for addressing the barriers various transportation modes present, personal stories and studies asking about the barriers to transportation. The previous work that has employed engineering and planning data structures and questions has been more sparse, but has been done previously. This work is old and is in need of an update. This report is based largely on the previous engineering and planning research and will hopefully serve as an update to that work, as well as beginning to address the concerns identified by the disability studies community.

This study provides much of the intended results, with barriers to transportation access and utilization identified and discussed for various modes. The travel demand characteristics of persons with intellectual and developmental disabilities also was determined, and showed a high reliance 
on being driven by their caregivers for trips which averaged less than 3 times per week. Questions about interventions or new infrastructure to address concerns with transportation identified that infrastructure changes to support non-motorized transportation would increase independence, but only if those modes were available to persons already. This contrasts with learning how to use a new mode, which was not seen as helpful for increasing independence. 


\subsection{LITERATURE REVIEW}

\subsection{Introduction disability}

The first portions of this section are intended to provide basic background and information relating to disability and the discipline of disability studies. These portions are not comprehensive nor complete, but provide the information required for the reading of this study and to answer questions which may arise from its conclusions. Understanding the cultural representations of people with disabilities addresses the apathy and negative prejudice which has and will continue to be a barrier to understanding issues and instituting solutions for all portions of life for persons with disabilities. Understanding how persons with disabilities have been treated over time introduces the reader to the underfunding and apathy of governments for people with disabilities. The history sections also addresses the origins of the current day issue of transportation and intellectual and developmental disabilities.

\subsection{Cultural Representations of People with Disabilities}

It is important to understand how persons with disabilities are represented in society, often they are represented as solely a physical manifestation of disability, erasing their personhood and their internal lives. These interpretations and views of persons with disabilities, especially those with developmental disabilities, allow us as a society to ignore the challenges posed to inclusion and integration of persons with disabilities into our society. This section will highlight three of the most common interpretations of persons with intellectual disabilities and how these representations remove the person with disabilities from their own stories and present barriers to discussing improvements to serve persons with disabilities.

The first interpretation to discuss is best represented by the character Tiny Tim in A Christmas Carol, and Jerry Lewis's telethons. In A Christmas Carol Tiny Tim is viewed as a physically disabled child who continues to have a positive demeanor about life. Tiny Tim has few lines and little is known of his personality beyond this, instead his purpose is to be a reflection for Mr. Scrooge. When Mr. Scrooge sees that his greed will cause Tiny Tim's death he is remorseful and changes his ways, therefore feeling good about himself in the process (Russel, 1998). Similarly, the telethons run by Jerry Lewis were ways for people to feel good about themselves. Giving money to a charity to help with Muscular Dystrophy gave people a way to feel good about 
themselves without addressing the parts of our society which are disabling to persons with disabilities (Longmere, 2017). These interpretations rely on an inherent goodness of persons with disabilities, as well as inherent pitifulness. Seeing persons with disabilities as helpless and pitiful denies them agency and the interpretations illustrated by Tiny Tim and Telethons are that persons with disabilities exist solely for persons without disabilities to virtue signal.

The next interpretation involves the greatly lowered expectations for persons with disabilities, leading to a hero/pity complex. This interpretation acknowledges the barriers in place for persons with disabilities to access society and therefore overly rewards any normal behavior (Tozer, 2017). This view does nothing to address the barriers faced by persons with disabilities, viewing the barriers as natural and while it does give persons with disabilities the credit of overcoming these barriers it does not encourage people to remove these barriers nor encourage further accomplishments (Vaughn, 2003). Thus, the focus on overcoming barriers for any everyday task again lowers the expectations for any person with disabilities and interprets the individuals as charity cases and deserving of pity (Feder Kittay, 2017). This continued view of persons with disabilities as pitiful ignores their potential and views their integration as a charity cause instead of as a way to allow everyone to contribute to society.

A common refrain heard by the author and others is that 'special children go to special parents/families'. This refrain is a small part of the interpretation that persons with disabilities, or their families, deserve to have their disability. This interpretation has been present for thousands of years and is present in holy scriptures. In John 9:3 Jesus heals a blind man, after which his disciples ask if this man was blind because of his own sins or because of those of his parents, Jesus replies that the man was blind only such that the power God had bestowed in him could be revealed (Braddock, 2002). When disability is viewed as either a blessing or a curse from a supernatural force it results in the view that barriers and exclusion for persons with disabilities is virtuous in its' discrimination, as God's work would be for naught if these barriers were not present and that overcoming these barrier is and should continue to be a normal part of life for persons with disabilities.

Understanding how our society views persons with disabilities is important to understand as we grapple with how to improve access, integration and services for persons with disabilities. These 
interpretations common in our society deny personhood and the value which persons with disabilities can provide. This study cannot be interpreted without addressing these issues and interpretations of persons with disabilities as inferior. Viewing persons with disabilities as deserving of integration and deserving of the independence and freedom persons without disabilities enjoy is important to addressing the issues facing the disabled community. This study is only an early step towards providing these strategies for inclusion and integration for persons with intellectual disabilities. Any results of this study, their implementation, and future research will have to continue to address and acknowledge these views of persons with disabilities in order to encourage changes to better include and integrate persons with developmental disabilities into modern society.

\subsection{A Brief History of People with Disabilities}

So long as there have been people there have been people who have different abilities, but rarely does one consider life for persons with the experiences of disabilities far in the past. One trope oft repeated is that ancient civilizations did not have people with disabilities, choosing infanticide instead of bringing a child seen as lesser into the community. While it is true that infanticide was not unheard of in ancient times, many people with disabilities lived into adulthood. Even in Sparta with its myth of mass infanticide, many persons with disabilities, especially those with cognitive impairments, would live into adulthood and be functioning members of society (Braddock, 2002). Because this paper cannot provide a complete history, we will review the history of people with disabilities in the United States; reviewing the treatment of persons with disabilities by society. Understanding this history is important to the context of this research and how including the experiences and needs of persons with disabilities during our transportation planning and engineering processes can diminish barriers to inclusion for persons with disabilities in society.

\subsubsection{The Promise and Failings of Institutions}

There were few resources available to persons with developmental disabilities in the American colonies or the early years after the American Revolution. A person with disabilities was likely to labor with the family if possible, if a family could not care for a person with intellectual disabilities there were few resources available other than imprisonment. Alm houses, poorhouses and other imprisonment continued to be the primary service available to people with mental illness and 
intellectual disabilities in the American colonies and until the middle of the 19th Century (Dorothea Lynde Dix, 2019). Ben Franklin and Thomas Bond founded the first hospital for persons with disabilities and mental illness in Philadelphia in 1752, Montreal established the first mental hospital in the Americas in 1694 (Braddock, 2002). As more states were added to the union varied approaches to people with disabilities were taken, Kentucky used a bidding system where persons with disabilities were put up for auction and families willing to take care of the individuals would bid for how little the state had to pay them to care for the individual for a year (Braddock, 2002). These treatments were unethical and were about to change.

From 1810-1840 reformists such as Dorothea Dix traveled the country and advocated for the ethical treatment of people with disabilities and mental illnesses. This work resulted in many legislatures building new asylums and hospitals, acknowledging the inhumane conditions of 19th century prisons were not appropriate for people with developmental disabilities. The new facilities were intended not only to provide humane treatment and housing for persons with intellectual disabilities, but also provide education and training, with the goal of finding private employment for people with disabilities and providing as much independence as possible.

While it was acknowledged that housing persons with intellectual disabilities and mental illness in prisons was inhumane, a reluctance to raise taxes meant that the asylums that were built were inadequate and understaffed. These underbuilt facilities were also tasked with housing large numbers of formerly incarcerated persons with developmental disabilities and mental illnesses, as jails and prisons excused themselves from housing persons with mental illness and intellectual disabilities (Braddock, 2002). These factors overwhelmed the new systems of asylums just as they were starting, and they struggled to provide adequate services. The ideals of mostly independent persons with disabilities was also damaged by the close of the Civil War as returning soldiers pushed people with disabilities out of the economy, and recessions put already scarce state resources under strain. Asylums, which were already underfunded, became workhouses as they tried to fund themselves with the labor of people with disabilities (Braddock, 2002). This is the system that continued until the 1960's and 1970's and deinstitutionalization.

The segregation, isolation and disregard of persons with developmental disabilities and mental illness meant that the eugenics movements of the early 20th Century was unchecked within the 
confines of institutions. With a population deemed unfit to reproduce politicians pushed for sterilization laws starting in Indiana in 1907. These laws were struck down by courts until Virginia in 1924 passed a law and forcibly sterilized Carrie Buck, and in 1927's Buck V. Bell was upheld by the Supreme Court of the United States as a reasonable action to stop the spread of disease and the procreation of persons with disabilities (Buck V. Bell, 1927). The result of this decision and subsequent laws which were enacted allowing and mandating the sterilization of persons with developmental disabilities in most states led to what is estimated as over 65,000 persons who were believed to have intellectual disabilities being sterilized without their consent, nor the consent of family member. The practice of forced sterilization of inmates was found unconstitutional in 1942 but not for the disabled. Buck V. Bell has never been overturned and the discontinuation of forced sterilization relied on states repealing their laws and policies allowing for it. Forced sterilization is just one example of the abusive conditions found in institutions from the 1900's, with all sorts of abuse, including negligence and death, being present throughout institutions. These abusive practices only started changing as lawsuits challenged the conditions in institutions and advocates for the disabled rose to the highest levels of fame and power.

\subsubsection{Ending the Mass Facilities}

The civil rights movements included some improvements in civil rights for persons with disabilities as court cases deemed abusive practices illegal and advocacy against the abuses of institutions became more prominent. These led to the slow dismantling of the large institutions which housed most persons with disabilities.

Into the 1960's conditions in institutions and the treatment persons with disabilities were receiving were inhumane. Inattention and underfunding allowed the aspirational reforms of the previous century to rot into prisons for persons with disabilities; segregated from the population and without hope of improvement or rehabilitation. This started changing in the mid 1960's through legal action, especially legal action which established that there was a right for treatment for all people in the custody of the government, including the institutionalized. In 1962 Charles Rouse was tried for carrying a weapon without a license, found not guilty by reason of insanity and was institutionalized, four years later and still in the institution he sued, asking for adequate treatment. Rouse v. Cameron (1966) established that the institutions, established for caring for persons with intellectual disabilities, were not acting in a fashion of rehabilitation and therefore were illegally 
acting as prisons, focusing on punishment instead of rehabilitation (Ferleger, 2019). The ruling determined that persons who were civilly committed to institutions may be held for as long as treatment required, but that they must be provided treatment. Further, this ruling rejected the argument that a lack of funds justified the insufficient medical treatment provided. These principles continued to be supported and extended to all individuals in lawsuits such as Wyatt v Stickney (1971), Welsch V Likins (1974), Jackson v Indiana (1972), O’Conner v Donaldson (1975) and continuing through the Olmstead Vs L.C. (1999) decision. These decisions collectively established that all persons can improve their mental capacity or condition with appropriate therapies, and that mental institutions must provide treatment in the least restrictive manner, lest they become prisons by another moniker, and that services must be offered outside of the institutions, and in community settings if possible (Olmstead Decision, 2019). These rulings and various laws passed in this timeframe started the legal framework for deinstitutionalization and integrating persons with developmental disabilities in their communities as much as practical.

This movement towards smaller scale and more integrated housing options for persons with intellectual disabilities has led to today, with institutionalized populations dwindling and group homes and other quasi-medical settings being introduced. While these facilities can and do provide basic services they cannot provide job training, employment, or a large enough population to create a whole community; requiring persons with disabilities to seek these services and activities outside of the facility, requiring travel to complete these tasks, create community and access services. This leads to the reason for this investigation, now that services and persons with disabilities are both dispersed throughout communities understanding how persons with intellectual disabilities travel is imperative to improving the accessibility of our communities to persons with developmental disabilities.

\subsection{Accommodations and Challenges in Modern Life}

As residential services have become more dispersed and integrated into communities the model for providing services to persons with disabilities must adapt. Services cannot be provided in one location without considering how persons with intellectual disabilities will reach them. This means that despite efforts to provide more services, find supportive jobs, or otherwise provide opportunities for persons with disabilities many are left out; unable to reach the opportunities available. While there are ways governments and agencies try to provide access to persons with 
disabilities in order to allow for access these strategies are underfunded, overwhelmed and unreliable. Because persons with intellectual disabilities cannot usually drive themselves, they are reliant on other ways to get around their communities. Common methods of transportation include fixed route transit, paratransit, transportation provided by the service providers, and being driven by caregivers. This section of the paper will establish how transportation barriers continue to keep persons with intellectual and developmental disabilities from opportunity and discuss new ideas to address these issues.

Fixed-route transit systems can be complex and challenging for many people, but for persons with any sort of disability the transit systems can be even less accommodating (Weisgerber, 1991). While transit training courses designed for persons with intellectual disabilities are available, they are resource intensive and inadequate for many persons with severe developmental disabilities. In addition, the accessibility and mobility provided by fixed-route transit is typically far below that of personal automobiles (Lindeke, 2019). While the fixed-route transit systems may fulfill some of the transportation needs of persons with intellectual disabilities, they are inefficient and cumbersome for providing access to all of life's needed trips, especially considering that service providers for persons with developmental disabilities do not have the budget to spend on rent, and therefore are on the outskirts of the transit system (Barnes \& Mercer, 2006).

This leaves many persons with disabilities relying on other forms of transportation for some or all of their trips. Paratransit is a well-known service for persons with all types of disabilities, it is an expensive service to provide, often unreliable, and has rules and regulations which are confusing and arduous for users (Cohen, 2018). Some of these rules include scheduling days in advance, allowing a 5 minute pickup window for the rider but a 1 hour or more window for the provider, a limited number of missed rides before being kicked off of the service, and being stranded when return trips were cancelled or appointments ran long (Wasfi, et al. 2009). Some facilities or service providers provide their own transportation to and from services and job sites. Other trip needs must be met by the individual themselves or by a caregiver providing the transportation. The available transportation poses a major challenge for everyday trips and activities for persons with intellectual disabilities. These challenges are reflected both in research and in the news. 
The National Core Indicators Survey asks persons with developmental disabilities about various aspects of their lives and if additional services are needed. Despite Minnesota respondents reporting they can make trips they need to make $96 \%$ of the time, and trips they desire $86 \%$ of the time; $21 \%$ of respondents indicated that these services needed improvement or were inadequate. In Oregon the numbers were 95\%, 84\% and 22\% respectively. Additionally, when comparing between 15 different categories of possible services which need improvement, transportation tied with 'Assistance finding, changing or maintaining jobs' and 'Social or relationship issues or meeting people' at 10\%, the highest of all categories (In Person Survey, 2018-2019 Final Report ,2019). Transportation as a barrier can be further illustrated by the news media.

The issues caused by inadequate transportation for persons with intellectual disabilities is evident in today's newspapers. The Seattle Times wrote about the difficulties of persons with intellectual disabilities finding and getting to work in small towns and rural areas throughout Washington in 2016, specifically noting access as a barrier (Pratt, 2016). In 2015, the Minneapolis Star Tribune wrote about similar issues with access to services, socialization and employment in a multipart series (Serres, 2015). The same can be seen across the country, with a quick review finding examples in Chicago (Greenfield, 2019); Baton Rouge (Burkes, 2019); Columbus, Ohio (Zachariah, 2019); Portland, Maine (Staff, 2019); and Bend, Oregon (Rees, 2013; Bannow, 2016). All these articles report that transportation availability and reliability are barriers for persons with intellectual disabilities obtaining employment, services, shopping or living everyday life. This leads to a clear thesis, that the current systems are not adequately serving persons with disabilities.

Acknowledging these gaps in service, local governments are starting to contract with transportation network providers (TNPs, i.e. Uber and Lyft) to provide rides for persons with disabilities in a more responsive manner (Clarey, 2019). While the idea of on-demand transportation for persons with developmental disabilities may be promising it is not without significant barriers. TNP companies themselves are claiming that they are not transportation companies, thereby avoiding compliance with the Americans with Disabilities Act (ADA) and associated regulations (Rubenstein, 2018). There are concerns about the safety of users of TNP services, which may be exacerbated when the users are vulnerable adults, and the two largest modern TNP companies (Uber and Lyft) are not profitable (Newcomer \& Zaleski, 2019). Individually any of these issues raises concerns for the effectiveness and sustainability of utilizing 
TNP services as a replacement for existing services. Together, these concerns show that there are still major challenges to overcome for TNPs to become a viable service for widespread use by persons with developmental disabilities.

\subsection{Previous Research and the State of the Knowledge}

One challenge in predicting how various interventions, such as the advent of TNPs, will affect persons' with intellectual disabilities independence is that there is a lack of research on the travel behavior of persons with developmental disabilities. The reviews on transportation options and access for persons with developmental disabilities is limited, but includes self-reported issues from individuals, reported issues from service providers, and surveys which this study attempts to emulate and expand upon. Reviewing previous work here ensures that this survey will be consistent with previous work, be useful to researchers and practitioners in the field, and will make this study more likely to contribute to the foundation of future research.

Persons with intellectual disabilities and those who assist them will often speak openly about the challenges posed by transportation options available to them. A project including oral histories in New York City group homes found that many resources were lacking, including transportation. Transportation needs were the dominating factor when deciding where and when persons with disabilities took recreational trips. The only relevant mode of transportation for the residents of the facility was for volunteers or staff to drive the residents to outings; planning and scheduling the events around when drivers were available and cancelling events when not enough volunteers were available (French \& Surain, 2012). An ethnography of a group home in New York slightly before the oral histories project detailed similar struggles with transportation, especially for recreational trips (Levinson, 2010). Other trips from these residential facilities were documented as more regular and therefore more able to utilize other modes of transportation, with employed members of the group home using the public transit system to access their jobs, and those who were headed to a day program were transported by a van from the program (Levinson, 2010). Relying on individuals for transportation needs limits independence, as all activities have to be planned around the volunteers' and staffs' schedules and willingness to participate (Bradley, et al. 1994). That everyday commute trips were not incumbent on caregivers is a step towards independence but still required a consistent schedule set far in advance. 
Service providers also note their difficulties in maintaining access for persons with intellectual disabilities to reach them. As noted in the section above, service providers are often unable to afford the rent in a downtown or transit rich environment (Barnes \& Mercer, 2006), therefore other transportation options have to supplement public transit. Large service providers and sheltered workshops are able to achieve this using a school bus style system (Gardner, et al. 1988), but this reliance on specialized transport is also unideal, being called "ideologically unbearable" by advocates of normalization (Brown, et al. 1991). While having transportation provided by the destination may be unbearable as a long term solution it is currently one of the only ways to connect large numbers of dispersed persons with intellectual disabilities, and provides safe, reliable transportation to services which might not have other accesses.

Finally, studies and surveys for persons with intellectual disabilities show the general travel patterns of persons with developmental disabilities and barriers to access. Travel specific surveys of adults with intellectual disabilities are not common, with only two well documented surveys being found by the author within the past thirteen years. The first is from Hennepin County, Minnesota in 2006 (Wasfi), and the other focused on autistic persons in New Jersey in 2009 (Feeley). Barriers identified included poor services through paratransit, limited transit training for adults with disabilities, and fears of crime. Frustration with dependency on persons without disabilities and with the transportation options available to the persons with disabilities is also a theme which occurs throughout both studies. While Feeley did not consider the purpose of trips and mode share independently, they did ask individuals what their primary modes of transportation were. Nearly $85 \%$ of respondents with severe mental impairment identified that friends or family were a primary mode of transportation (more than one response was allowed, with $140 \%$ reported in total) (Feeley, 2009). In Wasfi's report (Hennepin County, MN) the mode split was reported by trip purpose for work and shopping trips. Work trips were reported to have a very high prevalence of walking, with over $40 \%$ of all respondents identifying walking, $16 \%$ using transit, and 10\% using paratransit as their primary form of transportation for work trips. This compares to shopping trips where $14 \%$ of respondents identified walking as their main mode of transportation, $3 \%$ identified using transit, and 59\% reported using some sort of private vehicle (Wasfi, et al. 2009). This discrepancy in trip purpose and mode again reinforces what is seen above, that usual trips that can be planned can utilize more independent modes, whereas trips which occur with less frequency and certainty, such as shopping, rely on private vehicles. 
The overall state of the knowledge for the travel behaviors for persons with intellectual and developmental disabilities is poor, with few published studies and reviews. Much of the data and results are older than would be useful, and how modality and trip purpose connect is not considered except for work and shopping trips. This study should serve as an update to these previous works, as well as expand on the questions of trip purpose and mode choice, asking about mode choice for each trip purpose. 


\subsection{METHODOLOGY}

This study is intended to serve as a base for further studies and provide some recommendations on how to increase the independence of persons with disabilities through our transportation systems and infrastructure. Thus, the survey had to include many different aspects in order to determine where further investigation is needed, these aspects were reflected in the sections of the survey. Trips by purpose and mode choice, generalized opinions on modes utilized and finally questions and statements about the abilities of the participants. These sections made up the core of the survey and each section is valuable by itself but combined they may help to determine specific issues to be addressed or investigated to reduce barriers to transportation, and therefore community and inclusion, for persons with intellectual disabilities.

\subsection{Survey Instrument}

To address low response rates of traditional travel surveys utilizing travel diaries, and to capture activities which are less regular and/or frequent for persons with disabilities (Working in the Community, 2012) the survey is constructed to be completed in one sitting. Simplifying the survey and ensuring it is not burdensome for participants to complete also prevented inclusion of each destination, instead opting for sorting trip purposes by the participant. These simplifications will be affected by self-reporting biases and errors, but it makes the survey more accessible and more able to capture the total life of persons with intellectual and developmental disabilities. This style of travel survey has also been used previously including in a previous study determining the unmet travel needs for developmentally disabled adults in the Minneapolis-Saint Paul metro area (Wasfi, et al. 2009). The positives of including more aspects participants' lives was deemed to outweigh the negative affect of a less accurate or precise study. A copy of the survey, with all questions included but modified to a physical format, is included in Appendix A. This survey and its protocol were reviewed and approved by the PSU IRB as exempt (study 196377-18).

The first section of the survey was trip purpose, frequency and modes. The trip purposes included reflect the National Household Travel Survey categories, and respondents are asked to select how often trips for that purpose are made. Once the respondent has answered how frequently a trip is made they are presented with the modes assumed available to persons with developmental disabilities, and allowed to select the top three modes of transport used to achieve trips for that 
purpose. This construction does not make it possible to determine exact mode share of any individual trip or trip purpose, but it does provide a rough estimate for the total travel and modes which are typically considered by persons with intellectual disabilities. These estimates will allow for focusing further investigations into different modes, with modes used commonly should be investigated for short term improvement and modes used infrequently should be investigated for further barriers to use and the utility of the mode for persons with developmental disabilities.

The survey then focuses on the respondents' opinions on four modes assumed to be accessible to most persons with disabilities. The four modes are mass transit, paratransit, walking and cycling. Modes from above which were not continued into this section include 'driven by family/friends' and 'transportation provided by destination'; these modes were not carried forward due to the immense variability in the access to these modes and how they may be provided. For each mode a respondent used, six questions about that mode were presented. These questions addressed issues which were seen in comments to both the research team and presented in other research. The concerns participants were asked to rate included their perceptions on the safety of each mode, both from a traffic safety and personal safety standpoint; the participants' abilities to navigate with each mode, both focusing on getting lost and following the rules of the system; the speed of travel; the physical exertion of travel; and the fears of being alone or vulnerable when using the mode. This section is not able to recommend specific treatments to address these concerns, only highlighting areas of concern or relative satisfaction. This section should highlight what should be further investigated regarding barriers and concerns to each mode.

The final section of the survey was intended to determine the general ability of persons with disabilities to utilize various methods of transportation, and individual portions of the systems. The questions start with asking if the respondent felt like they were able to be independent while traveling or had any say over their transportation choices. There is a question on if individuals can read a map, which would likely be important for infrequent, novel or new trips. The section closes with questions on the infrastructure of non-motorized transportation and if improvements would help persons with developmental disabilities access their desired destinations. Overall this section of the survey should allow for identifying if infrastructure changes, or further trainings for how to use current modes would best improve the independence of persons with intellectual disabilities. 


\subsection{Survey Distribution and Recruitment}

This survey was distributed through advocacy and support organizations for persons with developmental and intellectual disabilities in the Minneapolis-Saint Paul and Portland (OR) metropolitan areas. Before the survey was constructed, the author contacted these organizations to request their cooperation in distribution of the survey. The respondents to the survey were intended to be persons with intellectual and developmental disabilities, although several respondents required or used assistance in their responses. This method of distributing and advertising the survey ensured that the survey reached a broad population of persons with intellectual disabilities and was posited to be more likely to garner responses with a contact from an organization the target audience was familiar with rather than the research team.

The organizations identified for survey distribution included the ARC, the Autism Society, the Down Syndrome Association and the Highland Friendship Club. All these organizations focus on advocacy and supports for persons with developmental disabilities, and all except the Highland Friendship Club had chapters in both Oregon and Minnesota. These states were selected due to the author's hometown (Saint Paul, MN) and the location of Portland State University, additionally the similar sizes of the major metropolitan area in each state and general cultural similarities would allow for a comparison between the communities if each garnered enough responses

This system of survey distribution was inconsistent due to differences in the enthusiasm and willingness of organizations to forward the survey to their membership. Therefore, some organizations declined to participate in the survey, some organizations posted the survey on social media or included it in a weekly or monthly newsletter, and some organizations emailed specifically about the survey and introduced it to their membership. This varying level of enthusiasm led to the results below, where Minnesota garnered far more responses than Oregon. 


\subsection{RESULTS}

This section is intended to provide visualizations of the data and the data used to draw conclusions in this report. Introducing all of the information in one setting to allow for a complete picture when the results are discussed in the discussion section below.

\subsection{Demographics}

'After distribution by the Highland Friendship Club and Down Syndrome Association in Minnesota, and the ARC of Oregon and Autism Society in Oregon, there were 48 and 4 usable responses respectively. While these numbers represent the total number of respondents, not all questions were displayed to all persons, therefore many questions responses will not sum to the whole. Due to the low response rate from Oregon, these responses cannot be evaluated independent of those collected in Minnesota. How the survey was distributed in Oregon and Minnesota was different and likely accounts for most of this discrepancy and will be addressed in the conclusion. For now the responses from Oregon were not included due to the very low number of responses.

For Minnesota, the demographics of the sample are younger, more female, and whiter than the population, as seen in Table 1, Table 2, and Table 3.

Table 1 - Age of Respondents

\begin{tabular}{|l|l|}
\hline Age & \\
\hline $18-25$ years old & 14 \\
\hline $25-30$ years old & 15 \\
\hline $31-35$ years old & 2 \\
\hline $36-40$ years old & 7 \\
\hline $41-45$ years old & 3 \\
\hline $46-50$ years old & 1 \\
\hline $51-55$ years old & 1 \\
\hline
\end{tabular}

Table 2 - Race of Respondents

\begin{tabular}{|l|l|}
\hline Race & \\
\hline White & 39 \\
\hline White, Hispanic or Latino & 1 \\
\hline Black or African American & 1 \\
\hline
\end{tabular}

Table 3 - Gender of Respondents

\begin{tabular}{|l|l|}
\hline Gender & \\
\hline Female & 28 \\
\hline Male & 15 \\
\hline
\end{tabular}

Over half of all respondents lived with relatives, four lived alone, and four lived in a group home, as seen in Table 4. This indicates that the level of independence is generally low, and that most of the respondents require some form of assistance. 
The sample's income is reported as less than the general population, with $80 \%$ of respondents reporting incomes lower than the area median income in Minneapolis-St Paul metro area $(\$ 53 \mathrm{~K})$, as seen in Table 5. A lower median income could be expected, as persons with disabilities have many barriers to gaining employment.

Table 5 - Annual Household Income of Respondents

\begin{tabular}{|l|l|}
\hline Annual Household Income \\
\hline Less than $\$ 10,000$ & 25 \\
\hline$\$ 10,000-\$ 14,999$ & 8 \\
\hline$\$ 15,000-\$ 24,999$ & 6 \\
\hline$\$ 35,000-\$ 49,999$ & 2 \\
\hline$\$ 50,000-\$ 74,999$ & 2 \\
\hline$\$ 75,000-\$ 99,999$ & 3 \\
\hline$\$ 100,000-\$ 149,000$ & 4 \\
\hline More than $\$ 200,000$ & 2 \\
\hline
\end{tabular}

Table 4 - Living Situation of Respondents

\begin{tabular}{|c|l|}
\hline Living Situation & \\
\hline Apartment & $\mathbf{8}$ \\
\hline I live alone & 3 \\
\hline Non-Relatives & 4 \\
\hline Relatives & 1 \\
\hline Group Facility & $\mathbf{4}$ \\
\hline Group home & $\mathbf{4}$ \\
\hline Non-Relatives & 4 \\
\hline Other (not specified) & $\mathbf{2}$ \\
\hline Relatives & 1 \\
\hline Private Home or Condo & 30 \\
\hline Non-Relatives & 1 \\
\hline Other (not specified) & 1 \\
\hline Relatives & 27 \\
\hline I live alone & 1 \\
\hline
\end{tabular}

There were 33 respondents who identified with specific intellectual disabilities and 14 identified with specific physical disabilities. The most common specific Hive alone intellectual disabilities were Down syndrome (12) and Autism spectrum disorder (10), while cerebral palsy was identified as the most common physical disability (8). This does not preclude physical or mental limitations not reported, and care should be taken to acknowledge that persons may have answered the combined question with only the information they wished to provide or which they thought most relevant at the time.

\subsection{Current Travel Behavior}

From Figure 1, the most common destination on a daily basis is work and/or schools and day programs. On a weekly basis, shopping, recreational and restaurant-based trips all are more common destinations than schools and day programs. 


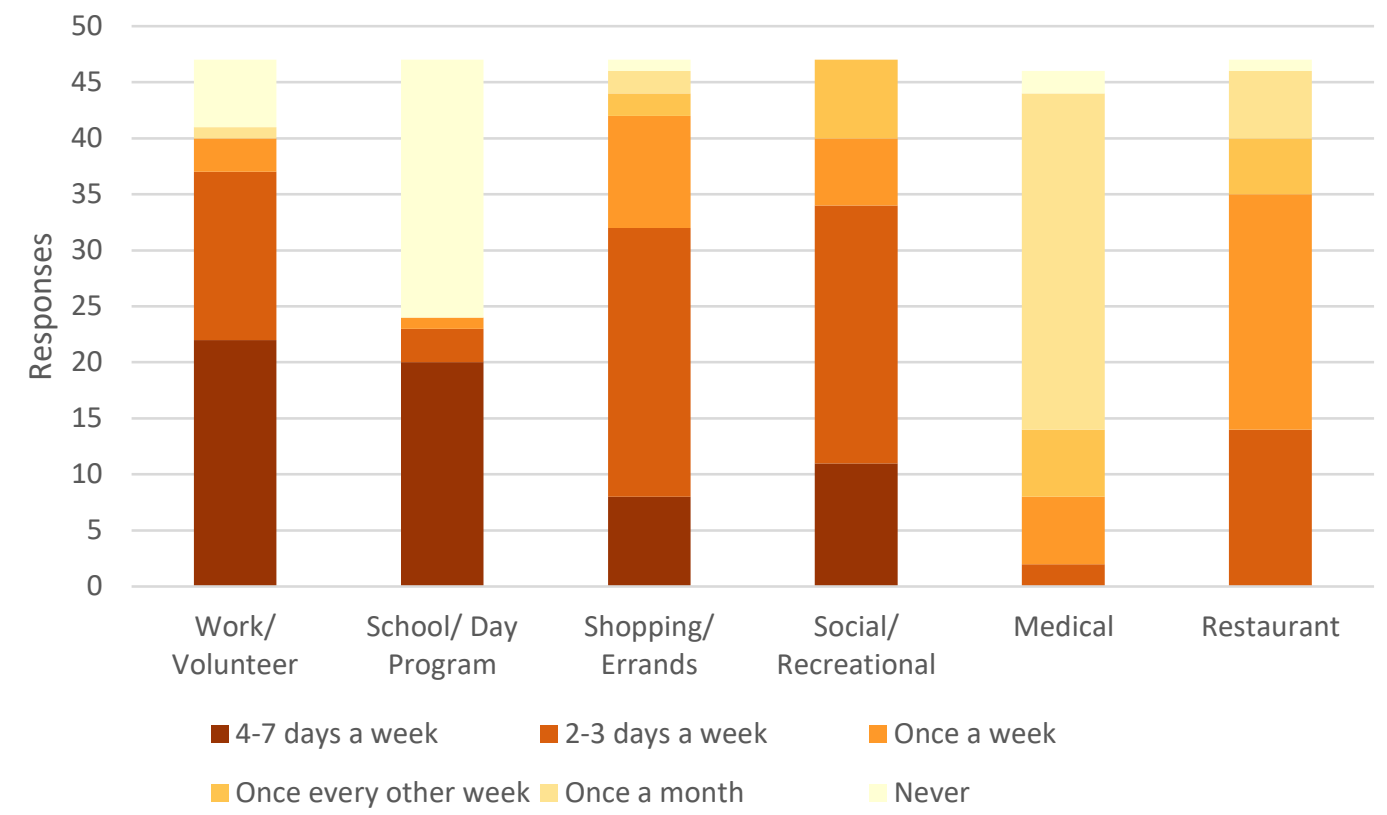

Figure 1 - Frequency of Trips by Trip Purpose

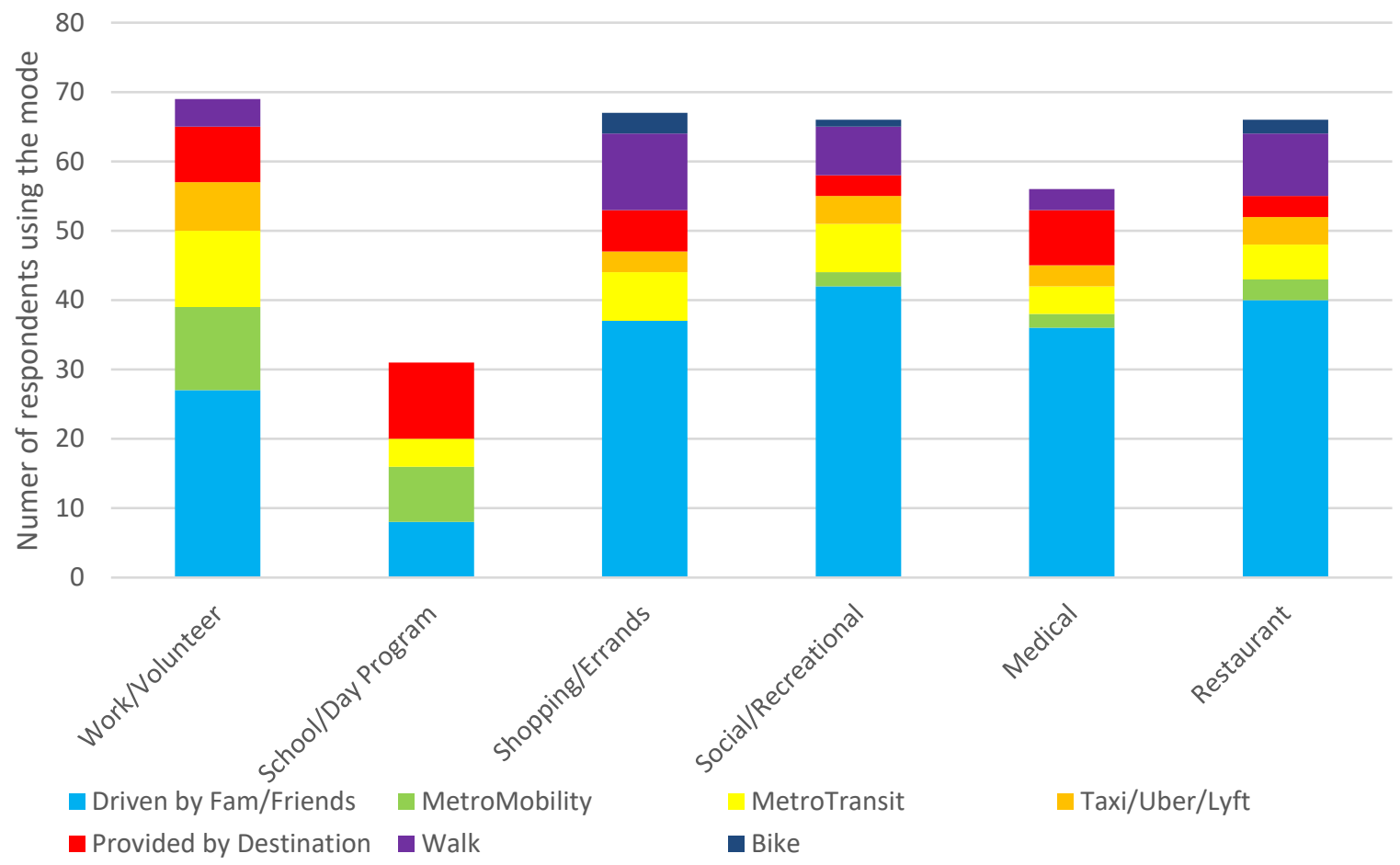

Figure 2 - Modal Split by Trip Purpose

Figure 2's columns do not represent a percent of total use, due to respondents being able to select their top three modes for each destination. This cannot determine mode choice, but instead 
highlights modes of transportation that are used by many respondents, and which trip purposes have more varied mode share.

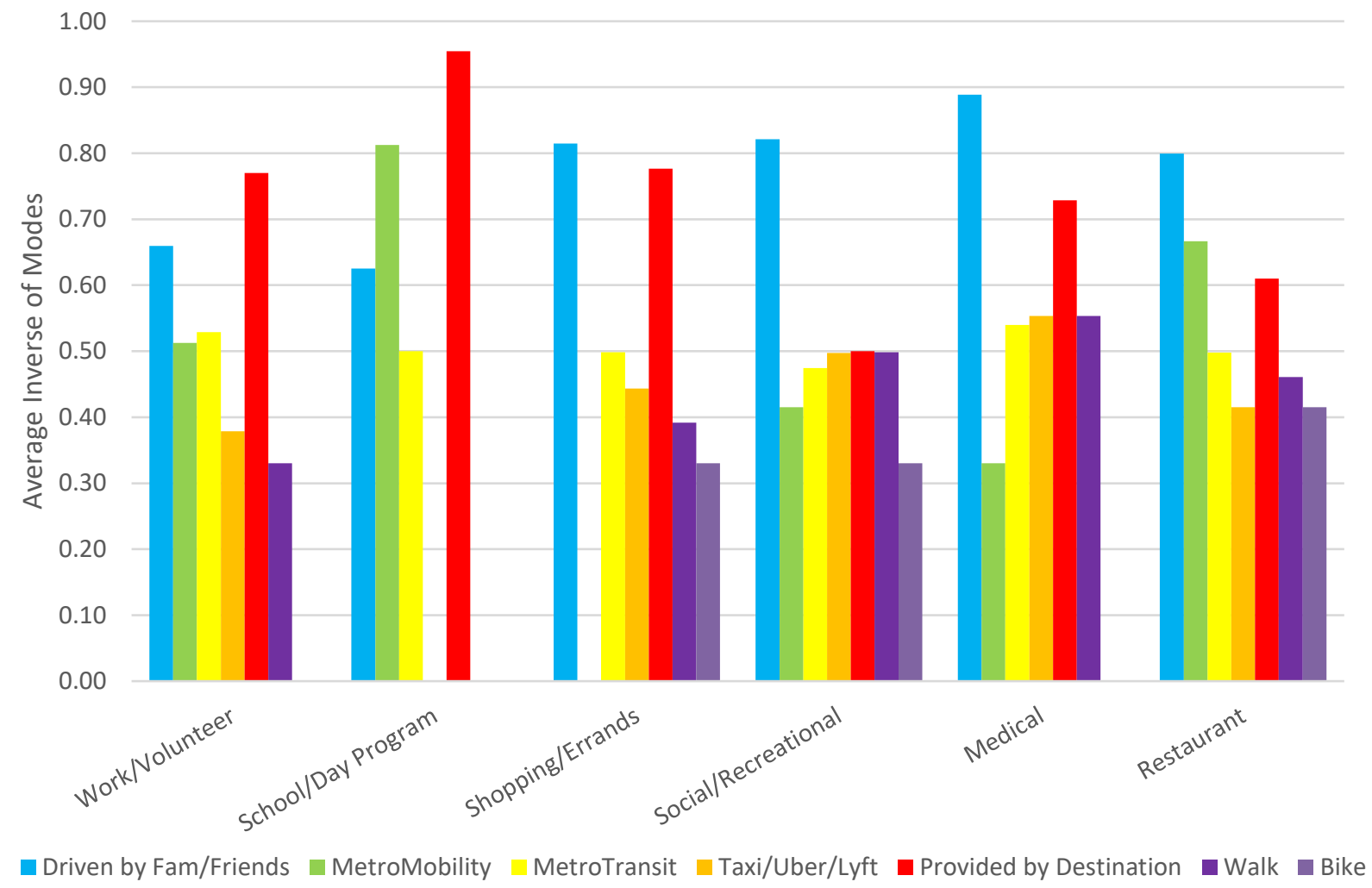

Figure 3 - Respondents' Dependence on Mode by Trip Purpose

Figure 3 details how reliant respondents are on the modes they selected, by weighting their responses for how many modes were selected and averaging these values. Therefore, a respondent who only used one mode to reach a destination would give a value of 1 to that mode for that purpose, two modes would be 0.5 and three modes 0.33 . Figure 3 shows the average of these values, which allows comparing and considering how different trip purposes are dependent on modes.

\subsection{Barriers to Access and Abilities of Respondents}

Questions relating to the general barriers persons with intellectual disabilities have or perceive towards each mode were also asked. These barriers were selected to reflect concerns from anecdotes and news coverage of transportation issues for persons with developmental disabilities, and to ensure that all modes could have a similar question asked. Walking is shown twice to 
represent everyone who reported walking for either transportation or enjoyment and again excluding those who reported walking only for enjoyment. Upon close inspection one may notice that the charts have an asterisk next to the number 3. This is by design as the value of the ' 3 ' response was adjusted to ensure better graphical representation. More on this can be read in the discussion.

Figure 4 shows that the top concerns for walkers were about traffic safety, getting lost and being alone for the entire sample, but when limited to only respondents who chose to walk (Figure 5, next page) for transportation the top three concerns were traffic safety, speed of travel, and overexertion (in a practical tie with getting lost).

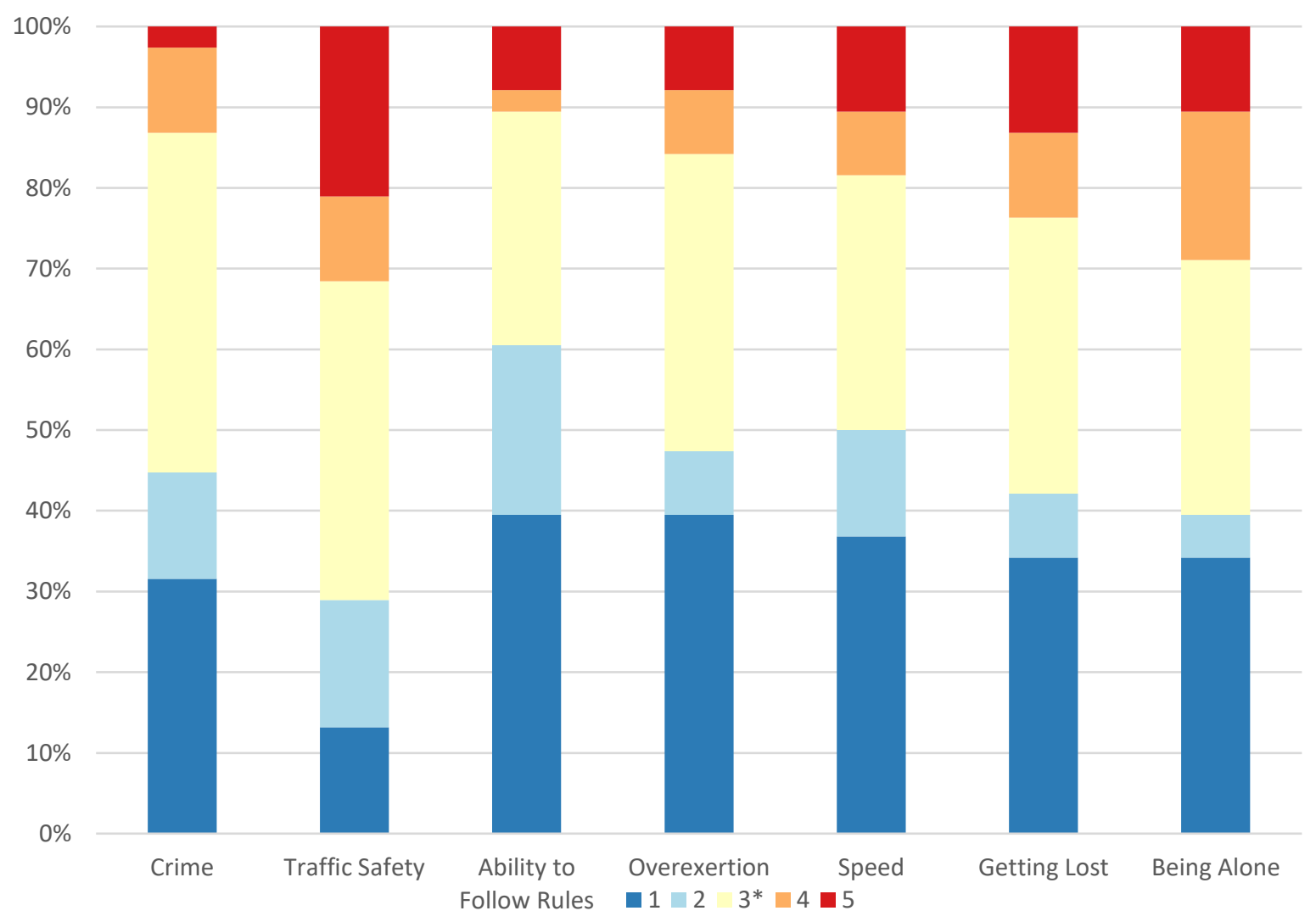

Figure 4 - Concerns about Walking 


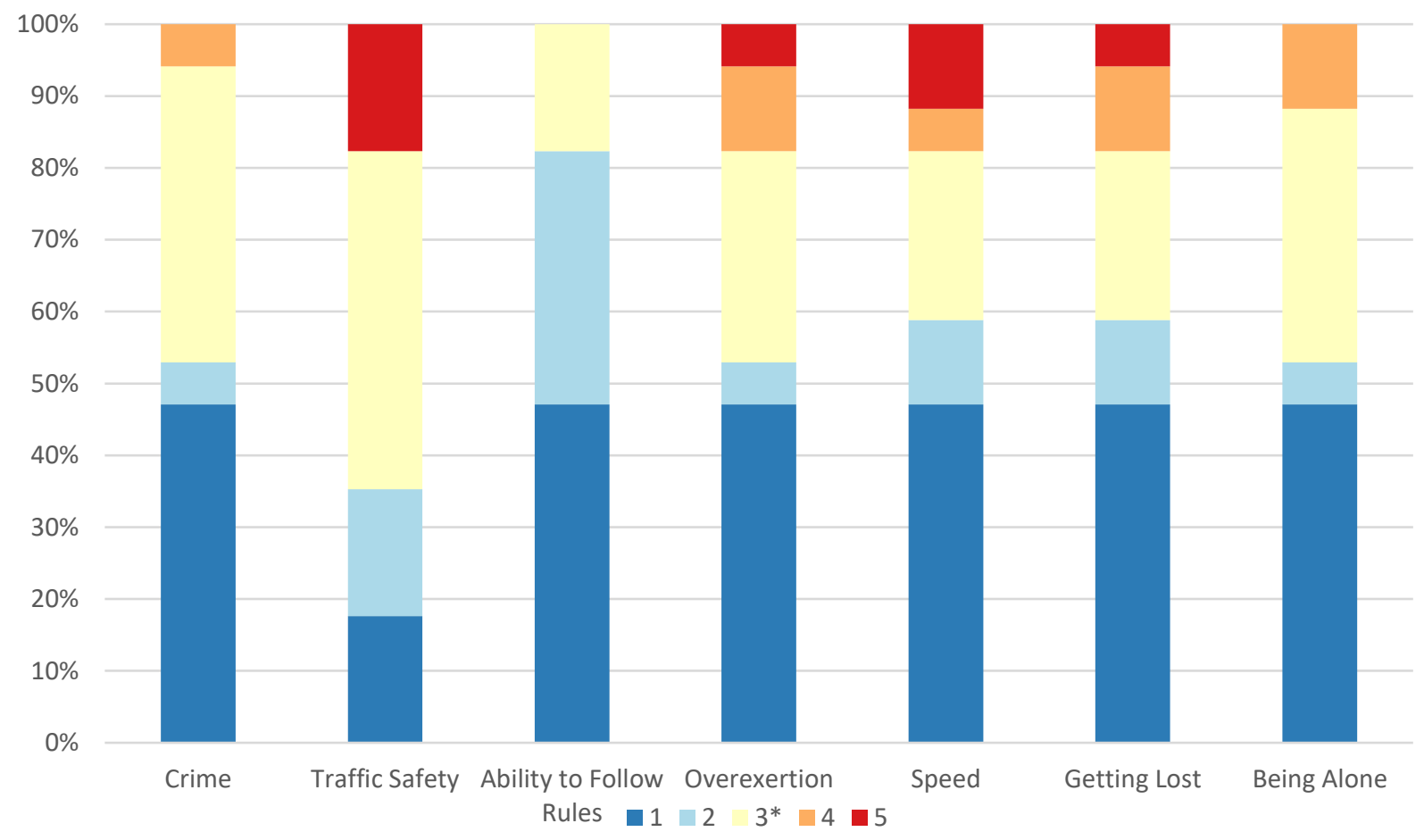

Figure 5 - Concerns about Walking (Only Respondents Who Walk for Transportation)

Figure 6 shows the Minneapolis-Saint Paul paratransit service MetroMobility had high concerns regarding the speed of the service. Few other concerns were expressed, with over half of all users identifying every other suggested concern as less a 1 or 2 on the 5 point scale.

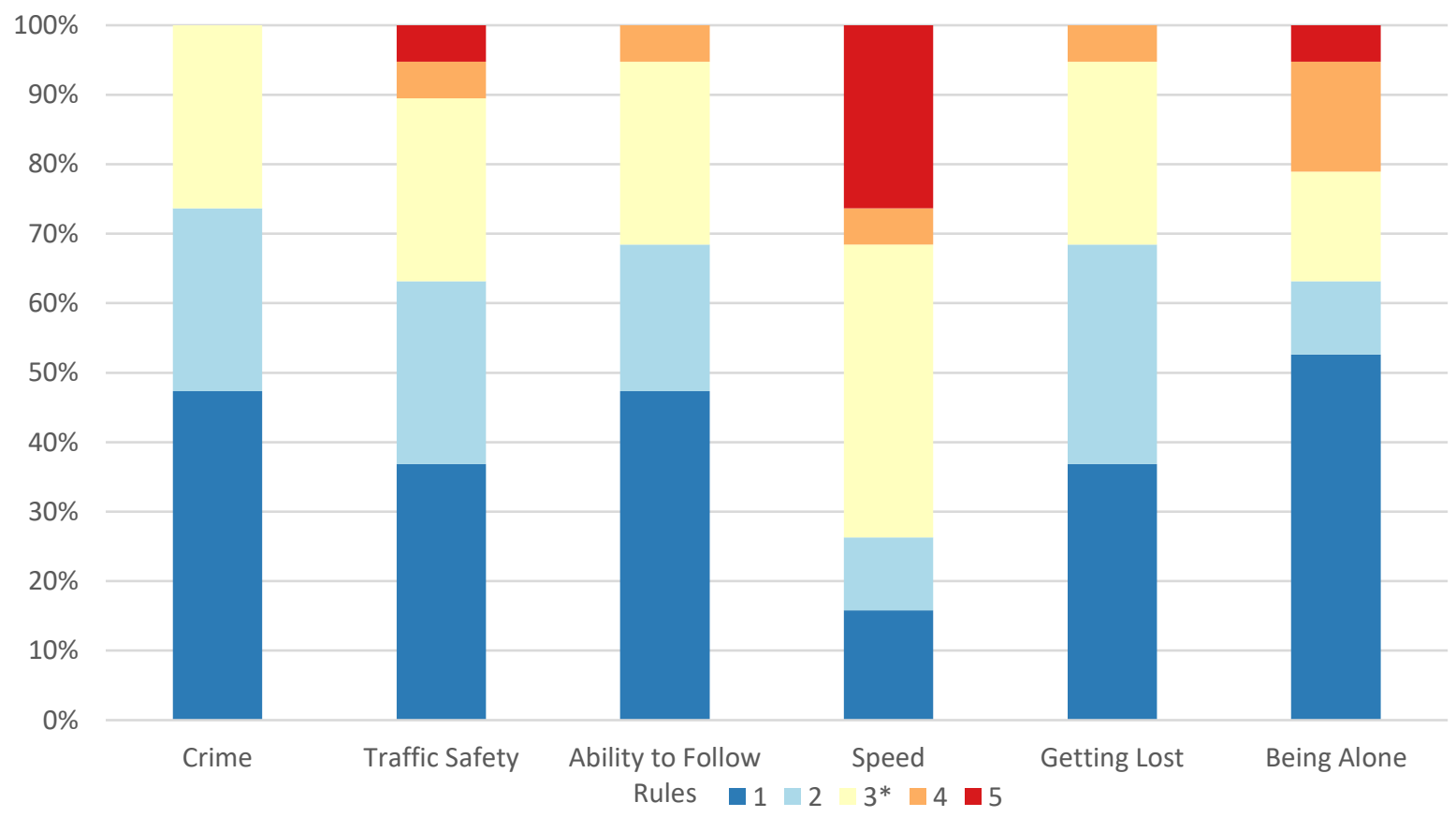

Figure 6 - Concerns about Paratransit 
Figure 7 shows Minneapolis-Saint Paul transit service provider MetroTransit similarly had many positive ratings from its users, but with concerns about crime, being alone, getting lost and the speed of the service still being present.

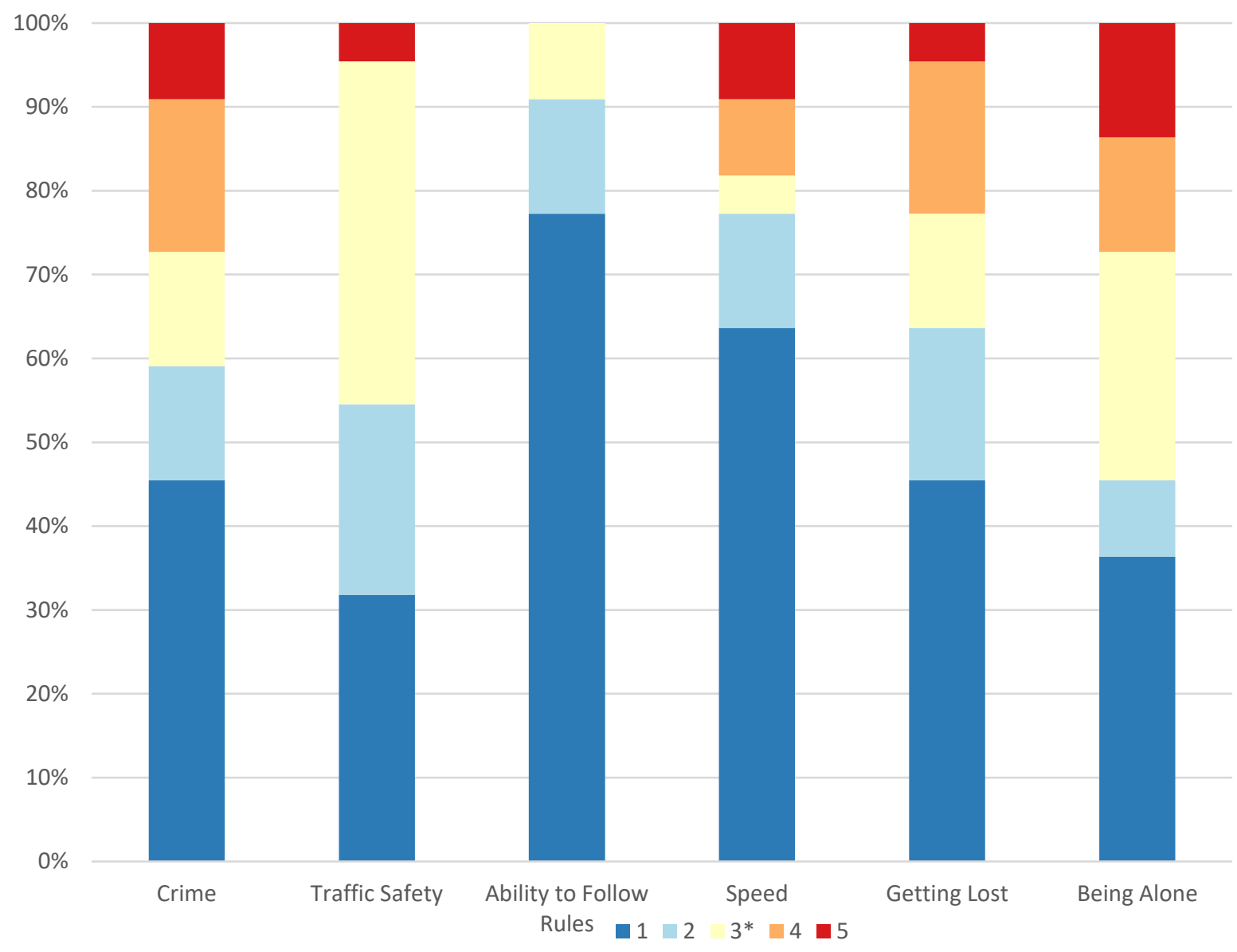

Figure 7 - Concerns about Fixed-Route Transit Service 
Bicycling was considered with all respondents together, as only 5 persons said they used bicycling for transportation. Figure 8 shows that respondents had high concerns with bicycling and traffic safety, following the rules of the road, and being alone.

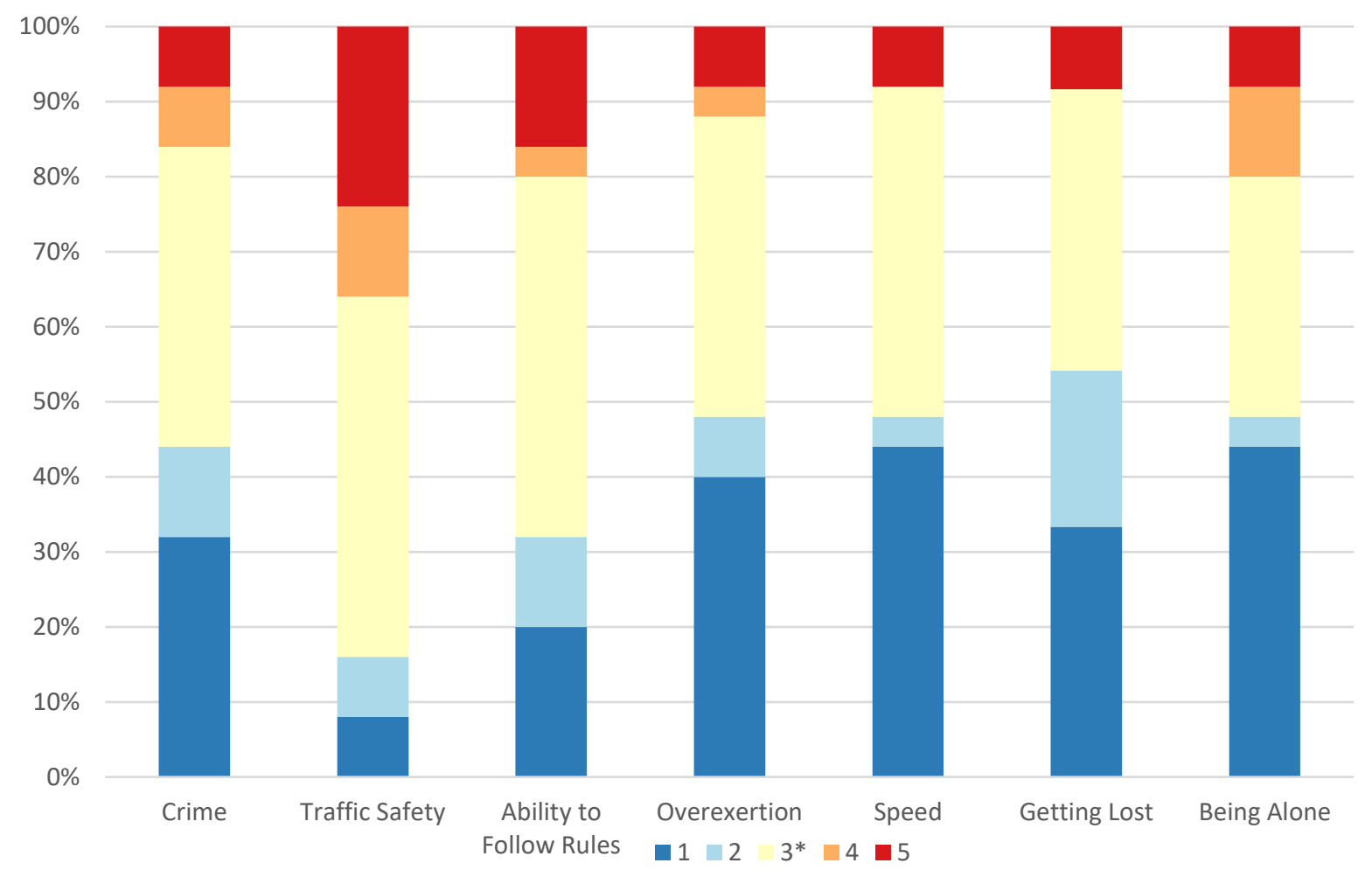

Figure 8 - Concerns about Cycling (All)

In addition to these charts showing the general barriers to modes, 3 questions on the abilities of the respondents were asked and are represented in Table 6. Independence in travel is highly correlated with choosing how to travel, and somewhat correlated with the ability to read a map.

Table 6 - Independence, Choice and Map Reading Ability

\begin{tabular}{|l|l|l|l|l|l|l|}
\hline Statement proposed & $\begin{array}{l}1 \text { (Strongly } \\
\text { Disagree) }\end{array}$ & 2 & 3 & 4 & $\begin{array}{l}5 \text { (Strongly } \\
\text { Agree) }\end{array}$ & $\begin{array}{l}\text { Correlation with “I Can } \\
\text { Travel Independently" }\end{array}$ \\
\hline I Can Travel Independently & 19 & 6 & 1 & 1 & 8 & 1 \\
\hline I Can Choose how to Travel & 19 & 6 & 4 & 4 & 3 & 0.81 \\
\hline I Can Read a Map & 26 & 6 & 0 & 1 & 3 & 0.68 \\
\hline
\end{tabular}

Finally, questions relating to non-motorized infrastructure were asked. These questions had very different response rates, and therefore the numbers of respondents per answer are shown on the chart in Figure 9. Overall, respondents enjoy using non-motorized transportation, and if they can 
use a mode, they anticipate increased independence with an expansion of infrastructure for the mode. However, learning to ride a bike was not seen as an improvement.

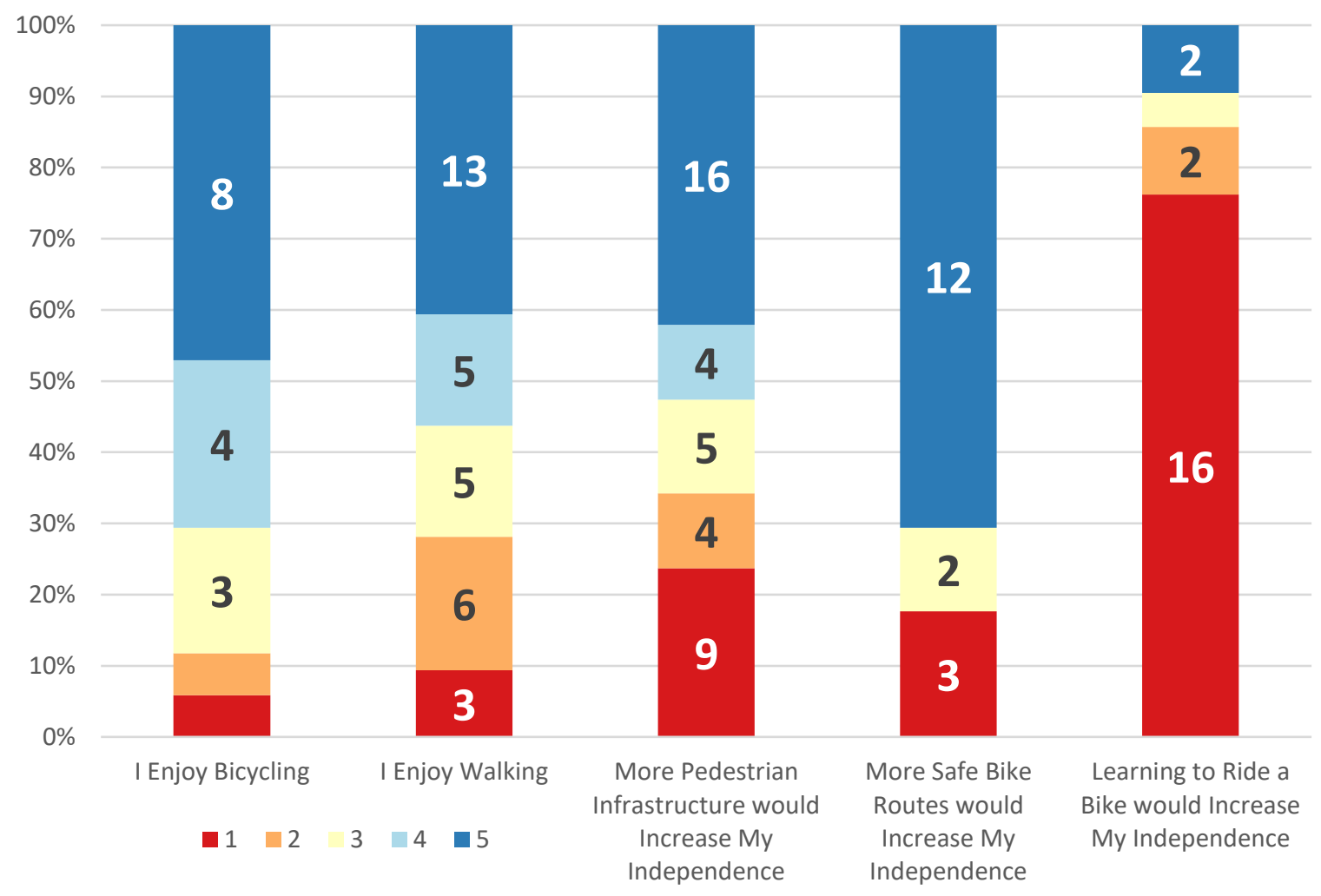

Figure 9 - Enjoyment of and Perceived Independence Gain from Non-Motorized Transportation

\subsection{Final Comments}

At the end of the survey, we provided a space for comments, some of which are listed below. The comments focused largely on issues with paratransit services; particularly the irregularity and unreliability of the service

\subsubsection{MetroMobility}

1. "I had to quit an internship because Metro Mobility could not provide service. I have been refused for a regular pick up twice."

2. "I have used Metro Mobility with others, and it's extremely unreliable, which creates lots of stress and anxiety."

3. "Need something more reliable than Metro Mobility" 
4. "Metro mobility won't pick me up from my current address as they say I am standby. I recently moved and they cancel my rides daily saying they can't pick me up"

5. "Nearby city of Lakeville does not support Metro Mobility so I am unable to work there or have recreation options. We are excited that there may be some safe options with Uber or Lyft"

6. "I do not like how long I have to wait for Metro Mobility sometimes, I do not like how long it takes to get home once I get picked up"

7. "Metro mobility is terrible. Sometimes I spend more than four hours per day getting to/from my day program that is only 15 minutes from home."

8. "Extensive annual background check for drivers. Metro Mobility expensive \& very slow. Vetted transportation service with reasonable rates for disabled individuals. Public transportation not always safest and not enough reliable Metro Mobility services. Wait times extremely long"

\subsubsection{Other Comments}

9. "I would be more afraid of getting lost if I walked or took transit alone, but I don't. I have a Metro Mobility card but don't use Metro Mobility because it's inconvenient, and have had poor experiences with it. I suppose if family didn't accompany me, I'd rely on it more."

10. "My employer is in Hudson and no one will drive me except friends or family. My mom can't use the funding because it's out of Minnesota."

11. "I have used Lyft to get to work. I have used Lyft 23 times. It is great."

12. " $[\mathrm{I}] \mathrm{t}$ would help if sidewalks and bus stops were better cleaned when there is ice and snow. there are often large mounds of snow, sometimes frozen after a large snowfall and icy sidewalks make it more difficult to walk to and from transit stops, better more frequent transit in suburbs (Maplewood) would make it easier for my son to get home from his school in Maplewood to Saint Paul and he could go to school on his own in the morning if there were more bus routes in the morning... right now he'd have to leave pretty early."

13. "It would be great to have cars to get me where I need to go that would be on time and reliable." 


\subsection{DISCUSSION}

The discussion will be split into four main sections. Considering how persons reach different destinations and their reliance on the modes to get them there, considering how different modes act and the strength and weaknesses of each, how persons with disabilities see their abilities and how improvements in the transportation system would change their independence, and discussion on the limitations and possibilities of errors in the study. These sections generally relate to the sections of the survey, and the analysis done through each section. Although they are discussed separately, the different sections inform and relate to each other to determine which modes meet the transportation needs of persons with intellectual disabilities, and the strengths and weaknesses of each.

\subsection{By Trip Purpose}

The results showed that two trip purposes were common for everyday travel, work and day programs. These trips also showed a greater variety in the modes utilized than other trip purposes. While being driven by family and friends is still a major mode of travel, for work and day programs the dependency was less, having an average dependency of 0.64 while no other trip purpose was under 0.80. Taking MetroMobility (paratransit) and having transportation provided by the destination were modes used more commonly to reach work and day programs and had higher dependencies than seen for other trip purposes. MetroMobility is especially interesting, because for no other trip purpose was it a reported mode by more than three respondents, yet between the two trip purposes 20 respondents reported using MetroMobility and had dependencies of 0.51 and 0.81. Being able to use MetroMobility for these daily, set trips might be a factor, as once a regular pick-up has been accepted users might be more reluctant to alter their schedule. In the comments section, Comment 1 illustrates this, as a respondent describes their reliance on MetroMobility, once they were no longer able to receive service the respondent had to quit their job with no other way to access work. Comment 1 also mentions being refused for regular pick-up, indicating that the respondent still wants to work and wants to try and access opportunity, but cannot due to the inability of the service to provide the transportation required. This also shows why transportation provided by the destination might be so high for these modes, as the ride is regular and predictable. This means there is no ability for persons with developmental disabilities to alter their workplace,

employer or schedule at will, reducing flexibility and opportunity. Other things to note about these 
trips is that overall, workers were less reliant on their modes of transportation than persons headed to day programs, this could be for a few reasons. Workers may be more independent and less likely to have a debilitating disability, therefore more able to use multiple modes to reach their destination; workers are less likely to have transportation provided to them and have a start of their shift, therefore using an unreliable service like MetroMobility might be fine for an occasional ride but cannot be the only method of reaching work otherwise rides might be cancelled or delayed beyond acceptable times; finally, persons with intellectual disabilities struggle to find a single source of full-time employment and might seek multiple part-time jobs. Having different jobs and jobsites might mean that respondents are using different modes for different jobs, even if the mode is relatively stable for each job. Determining which of these reasons is not possible with the data collected. Overall, daily trips use more varied transportation options than other trips and trips to work are more varied per person than trips to a day program. Persons in day programs largely depend on MetroMobility and the program itself to provide the transportation needed.

The next most common trip purposes are social/recreational and shopping/errands trips. These trips have a clear main mode of being driven by friends and family, with most respondents listing that as a mode of access, and for both trip purposes the reliance on being driven is over 0.80 . This is countered by the unused mode of MetroMobility, as no one reported shopping or running errands with MetroMobility, and only two respondents listed it as a mode they used for these trips with a dependency of 0.42 , meaning they both had other ways to achieve these trips. Not using MetroMobility may be driven by the unreliability of the service, long waits for pick-ups, and scheduling the return trips may be difficult to ensure a timely estimate which also allows time for unexpected delays in the shopping experience. The results of replacing MetroMobility with driven by family and friends makes sense for social trips as well; if the respondent was socializing with someone who can drive it may be simpler and easier to be picked up instead of setting up a ride with MetroMobility.

For the social/recreational and shopping/errands trip purposes, some interesting results lie in lesser used modes. MetroTransit (fixed route) and walking were the next most common modes reported for both trip purposes. The dependency of respondents on these modes was not high, between 0.40 and 0.50 , indicating that these modes are not the only ways to access shopping needs and social/recreation activities. This is interesting because unlike employment, shopping and 
social/recreation destinations are more able to be altered by the person, and therefore these results could be a hint at preferences in travel. When there are many options for where to shop, taking fixed route transit or walking is a preferred choice, even if it isn't the only choice available or made. It is also still interesting how many respondents reported that their transportation to shopping and errands was provided by the destination or a service provider, with 6 respondents choosing this and having a dependency of 0.78 , about the same as the dependency on transportation provided by destination for work trips. Trips to restaurants were less frequent but were similar in modes used and reliance to social/recreational trips.

Trips for medical purposes were rare, with a frequency of one trip per month (the lowest frequency provided) being the most common. Medical trips relied on being driven by friends and family, with a dependency of 0.89 . The next most important mode was transportation provided by the destination, with specialized medical transports to ensure people can access the care they need, transportation provided by destination had a dependence of 0.73 . Other modes used had very low numbers of respondents reporting their use. It is interesting that TNPs and MetroMobility were used relatively similarly, but TNPs had a dependency of 0.55 while MetroMobility had a dependency of 0.33 indicating all persons reporting using MetroMobility used all three of their options for the top three modes they used in reaching medical appointments. This finding is limited by the low number of responses, with only three people reporting using TNPs and four using MetroMobility for this trip purpose. If this would hold with more respondents or if the modes would converge would be important in determining if TNPs are better equipped to serve transportation needs of persons with intellectual disabilities than paratransit services.

\subsection{By Mode}

Seven questions intending to determine barriers and how to further investigate barriers for transportation were asked in relation to each mode. They revealed what concerns respondents had on various transportation modes.

Walking is a mode accessible to most people, even persons who have physical limitations and developmental disabilities can use pedestrian infrastructure to travel. Because of this, walking was considered in general, and by only respondents who reported walking for transportation. The main concern for walking was on traffic safety. Respondents listed concerns about traffic safety the top 
concerns for walking, with less than $30 \%$ rating the concern as a 1 or 2 out of 5 and over $30 \%$ rating the traffic safety as a concern of 4 or 5 , with over $20 \%$ of respondents rating their concern on traffic safety a 5 . This is nearly twice the number of respondents listing the concern as a 5 as any other concern listed. It is interesting to contrast this result with the relative comfort respondents have in being able to follow the rules of the road as a pedestrian, with $10 \%$ of respondents listing their concern as a 4 or a 5 , but over $60 \%$ listing their concern as a 1 or a 2 . From this it is clear that people with intellectual disabilities know a basic set of rules for being a pedestrian and are able to follow them but are still uncomfortable with walking due to concerns about other users and infrastructure. Respondents also listed getting lost or being alone as a level 4 or 5 concern over $20 \%$ of the time. These issues had more than $40 \%$ of respondents list them as a level 1 or level 2 concern. When the sample was limited to respondents who said they walked for transportation, the responses became less concerned overall, but for four concerns, the percent of respondents recording their concerns as a 4 or a 5 remained near $20 \%$, and these were speed, overexertion, getting lost and traffic safety. That respondents who normally walk are more comfortable walking is not a shocking result, as persons who walk for transportation are more likely to have built a confidence in their route and routine and if they have encountered a situation involving those concerns listed, were able to solve it in some way.

Cycling is an independent mode that could allow persons with developmental disabilities to address their transportation needs directly and could extend the range of mobility beyond walking distance. The concerns that were high for bicycle riders were traffic safety and the ability to follow the rules of the road. These concerns were greater than for any other mode. As a bicycle rider, one must follow basic driving rules, and must pay attention to a large number of stimuli while vehicles and drivers pass much closer than when one is walking; this may be more difficult for persons with intellectual disabilities, and this lack of separation is listed as a concern for many cyclists with and without developmental disabilities. While other concerns did exist, they were similar to the levels of concerns for other modes.

Respondents concerns using fixed-route transit highlighted specific areas of concern, but also noted specifically low levels of concern in other areas. The highest level of concern as compared to other modes was transit had a large concern about crime, with nearly $30 \%$ of respondents listing their concerns about crime as a 4 or a 5 . Being a vulnerable adult on transit has been a concern 
listed in previous studies' comments and anecdotally. Concerns about getting lost on transit were the highest of all the modes, with over $20 \%$ of respondents identifying getting lost as a level 4 or 5 concern. This is intuitive as getting on the wrong bus, missing a stop, or missing a transfer could result in a transit user being far from their intended destination. These concerns, similar to safety concerns for cyclists, do not extend only to persons with disabilities and are a reflection of concerns throughout the population. Finally, concerns about being alone were particularly high for fixedroute transit, with again near $30 \%$ of respondents identifying this as a level 4 or 5 concern. The concern about being alone being so high indicates that there are other concerns that are either assuaged by normally riding with others, or which are not addressed in the survey construction, and a more open-ended approach to determining barriers to use of fixed-route transit should be taken. Lastly, concerns not addressed in the survey itself is mentioned in quote 12 with concerns about accessing destinations, limited routes, limited frequencies, and difficulty reaching the bus stops are listed as concerns preventing the use of transit for an individual to reach his school. These concerns should be part of any more in-depth review of transit use for persons with intellectual disabilities.

MetroMobility (paratransit) had few concerns listed highly but comparing concerns to fixed-route service highlights dissatisfaction seen in the comments section. Paratransit had low concerns about crime on paratransit services with no one rating their concern a 4 or a 5 ; there are low concerns about getting lost, especially as compared to more involved modes like transit, walking and cycling; and paratransit has the most people rating their concern about being alone as a level 1 or 2 concern. Being in a separate vehicle, with only other persons with disabilities, aides and the driver is likely the cause of diminished concerns as there are few others to cause these concerns and the passenger is not the one in charge of paying attention to when it is their stop. The highest rated concern about paratransit was the concern about speed, this concern is especially noteworthy when considering the same concerns for fixed-route transit. Fixed-route transit had approximately $75 \%$ level 1 or 2 concerns about the speed of travel and $20 \%$ level 4 of 5 concerns, whereas paratransit had approximately $25 \%$ level 1 or 2 concerns about the speed of travel and $30 \%$ level 4 or 5 concerns. Since paratransit is supposed to deliver service in a similar timeframe as fixedroute transit, this chasm in concerns of level 1 and 2 is striking. Another area of discrepancy between fixed-route transit and paratransit is in concerns over following the rules of the service. For fixed-route transit, nearly $80 \%$ of respondents listed following the rules of the service as a 
level 1 concern, and an additional 10\% listing it as a level 2 concern. No respondents listed following the rules of service as a level 4 or 5 concern for fixed-route transit. For paratransit, nearly $50 \%$ of respondents listed ability to follow the rules of the service as a level 1 response, an additional $20 \%$ listed it as a level 2 concern. The discrepancy here could be explained by the rules of the service including being ready and prepared to go imminently as the vehicle arrives, and a few missed rides can disqualify a user from the service. Other explanations are provided by the comments, four of the comments shown in the results section specifically cite MetroMobility as having slow service or long wait times, and many others cite its unreliability as a service. These frustrations likely carried over into this portion of the survey and addressing these reliability and reasonability concerns would help address these higher concerns seen in this section.

\subsection{Abilities and Improvements}

The final portion of the survey included statement on the respondent's abilities, independence and how they believed gaining skills or infrastructure improvements could affect them. This section gives more context to the sections above but can also allow for active implementation of certain strategies to increase independence.

The first questions of this report asked respondents to rate how the felt about statements on their independence and choice about how to travel. It is clear from the responses that most respondents who disagreed that they could travel independently or that they have a choice in how to travel also disagreed that they had a choice in how to travel. This supports the notion that independent transportation involves choosing how to travel, and that choosing how to travel is difficult if your choices are limited by your independence.

Participants were asked if they enjoyed walking or cycling and both were seen favorably, although cycling was seen as an enjoyable activity by $70 \%$ of those who could ride. This enjoyment indicates that if active transportation were an available and prudent option, it may become a part of many of the respondents' travel behavior. Thus, if we can address the concerns above and ensure that opportunities are close enough for persons with developmental disabilities to reach, more persons with intellectual disabilities would be able to travel independently and have more control over their own lives. 
Issues seen above as barriers for persons with developmental disabilities include getting lost and traffic safety. Specifically relating to these were questions about reading maps and infrastructure improvements for bicyclists and pedestrians. From this it was determined that most respondents could not read a map at all, and there were concerns about being lost for most every mode. Ensuring that everyone could find a map and understand how to get home would probably help comfort people who might otherwise fear being lost. The availability of maps is increasing with the advent of the smart phone, so this could be as simple as teaching persons with intellectual disabilities on how to use that app and that device could be very beneficial.

Concerns about traffic safety were addressed with questions about pedestrian and bicyclist improvements. While $53 \%$ of respondents said that more sidewalks, crosswalks and pedestrian infrastructure would increase their independence, $71 \%$ of respondents who could cycle said that more safe bicycle route would increase their independence. This discrepancy could be addressed partially by the locations where walking may be a prudent option already having decent walking infrastructure, or a general distrust of drivers and discomfort with traffic safety. Overall, any nonmotorized infrastructure improvement was seen as benefitting the independence of persons with intellectual disabilities, at least those who can use the mode.

For those respondents who cannot ride a bicycle, a question was asked for if they would benefit from taking a bicycle riders training course. The response to this question was very negative, with only $10 \%$ of respondents indicating that this would increase their independence and over $75 \%$ saying that it would not increase their independence. This is very interesting when compared to the question for further safe bicycle routes, as increasing the number of safe routes was seen as increasing the independence of those who could ride very strongly. Explanations for this could be numerous, with individuals who have physical limitations likely not benefitting from the knowledge of how to ride a bicycle; bicycling still has many concerns with traffic safety and an ability to follow the rules of the road that would not be addressed by simply learning how to ride; and currently riding a bicycle is reported as a used mode for so few respondents in the first section that learning how to ride might not be a useful step in increasing independence with the infrastructure we have at this time. No matter the reason, the responses to this question show that increased knowledge on how to ride a bicycle will not massively improve independence for most persons with intellectual or developmental disabilities. 


\subsection{Addressing Challenges in the Survey}

The survey was distributed in Minnesota by several organizations with which the author has personal connections. Being seen as an insider and member of the broader community of families and friends of persons with intellectual disabilities disarmed and reduced the hesitation of Minnesota organizations, especially as compared to organizations in Oregon. This personal connection led to the organizations actively emailing and distributing the survey to their membership, while in Oregon organizations did not know who the author was, nor why this was any different from a myriad of other surveys and studies which may reach out for contact. This difference resulted in many fewer Oregonians receiving and completing the survey. This illustrates the importance of reaching out to communities now and working with them prior to asking for their cooperation or assistance.

For several of the questions based on concerns and abilities there were many apparent nonresponses, which may have been due to the design of this survey. The survey used sliders to illustrate the concerns of respondents, with a column being either blank or filled depending on the value reported. These sliders were set to a default of 3 and appeared to be an active response for persons taking the survey if left untouched; however, the responses only recorded if the slider was selected during the survey. This led to questions having vastly different response rates throughout the same section of the survey. To address this issue, if a question was displayed to a respondent and the respondent answered questions both before and after a blank response, that response was assumed to be active and given the value of 3 . This is non-ideal as we are unable to determine who intended to skip a question and who intended to give a response of 3 and assumed the default value would be recorded. The data were also analyzed using only the active responses, while overall trends were similar the data visualization was incomprehensible. Thus, in this study non-responses which fit the criteria above were assumed to be a response with a value of 3 . Future work should note this and avoid the error in the survey design to ensure the precision of the results. 


\subsection{CONCLUSIONS}

For persons with intellectual and developmental disabilities transportation options, and therefore independence, are limited. The issues with these transportation options are documented through surveys, stories, previous research, and through news sources. The concerns have started to be acknowledged by decision makers and they are considering new services to address the issues with current service; although these solutions may not be sustainable. A lack of quantitative knowledge on the travel needs and behaviors of persons with intellectual disabilities means that addressing these concerns, or even studying how to address these concerns is difficult.

This survey provided some of the baseline travel demand data needed to make decisions, determine barriers to use of various transportation options, and began to investigate how changes in transportation infrastructure would increase or alter the independence of persons with developmental disabilities. The travel demand portion of this survey showed that persons with intellectual disabilities are very dependent on being driven to their destinations by caregivers but for regular or frequent trips they exhibit independence and varied modes of accessing their destinations. The focus on barriers to use showed that MetroMobility is unreliable, walking and bicycling are too dangerous, and wayfinding concerns are present in all modes. The focus on furthering independence found that new infrastructure would be helpful, but only to those who are able to use the mode now. Learning how to use new modes without addressing the issues of the new modes will not increase the independence of people with disabilities.

This study was limited by a small sample size and a lack of previous research. Future studies should make a more concerted effort to introduce themselves to advocacy organizations, build relationships, and allow for more input by the organizations on the design of the study to increase participation. Future work should ask questions about the reliability of fixed-route transit and paratransit, the efficacy of transit training, and should follow the supplementing of paratransit with TNPs. Future research for non-motorized transportation should focus on what is considered safe, comfortable infrastructure for persons with developmental disabilities on bicycles or walking, and how to ensure persons with intellectual disabilities can use new traffic safety devices effectively. Finally, any further research on travel demand should move towards traditional travel demand 
surveys, collecting the locations of destinations in order to evaluate the location of future improvements. 


\subsection{REFERENCES}

Anonymous, Olmsteadrights.org. Olmstead Decision. https://www.olmsteadrights.org/aboutolmstead/. Accessed May 10, 2019.

Anonymous, Anti-Defamation League. A Brief History of the Disability Rights Movement. https://www.adl.org/education/resources/backgrounders/disability-rights-movement. Accessed Mar. 1, 2019.

Bannow, T. Central Oregon ride service fields thousands of complaints. Bend Bulletin, October 3, 2016.

Barnartt, S., and R. Scotch. Disability Protests. Gallaudet University Press, Washington, DC, 2001.

Barnes, C., and G. Mercer. Independent Futures. Policy Press, Bristol, 2006.

Bartlo, P., and P. Klein. Physical Activity Benefits and Needs in Adults with Intellectual Disabilities: Systematic Review of the Literature. American Journal on Intellectual and Developmental Disabilities, Vol. 116, No. 3, 2011, pp. 220-232.

Braddock, D. Disability at the Dawn of the 21st Century and the State of the States. American Association on Mental Retardation, Washington, D.C., 2002.

Bradley, V., J. Ashbaugh, and B. Blaney. Creating Individual Supports for People with Developmental Disabilities. Paul H. Brookes, Baltimore, 1994.

Buck V. Bell. October Term 1926, No. 292, 1927.

Burkes, C. Hiring Those with Disabilities Isn't Charity, It's Good Business. Business Report, April $15,2019$.

Clarey, D. Dakota County partners with Lyft to help those with disabilities get to work. St. Paul Pioneer Press, April 24, 2019.

Cohen, J. Poor Performance prompts overhaul of bus service for people with disabilities. Crosscut, September 7, 2018. https://crosscut.com/2018/09/poor-performance-prompts-overhaul-busservice-people-disabilities. Accessed March 21, 2019

Davis, L. The Disability Studies Reader. Routledge, New York City and London, 2017. Articles used in this book are as follows:

Introduction: Disability, Normality and Power - Davis, Lennard.

Disability and the Justification of Inequality in America - Baynton, Douglas

"Heaven's Special Child”: The Making of Poster Children - Longmore, Paul

"The Institution Yet to Come”: Analyzing Incarceration through a Disability Lens -

Ben-Moshe, Liat 
Selections from Stigma - Goffman, Erving

Narrative Prosthesis - Mitchell, David and Sharon Snyder

Centering Justice on Dependency and Recovering Freedom - Feder Kittay, Eva

At the Same Time, Out of Time: Ashley X - Kafer, Alison

The Autistic Victim: Of Mice and Men - Freeman Loftis, Sonya

DePoy, E., and S. Gilson. Studying Disability. SAGE Publications, Thousand Oaks, CA, 2011.

Editors, History.com. Dorothea Lynde Dix. https://www.history.com/topics/womenshistory/dorothea-lynde-dix\#section_2. Accessed Mar. 20, 2019.

Feeley, C. Evaluating the Transportation Needs and Accessibility Issues for Adults on the Autism Spectrum in New Jersey. Transportation Research Board, Vol. 89th Annual Meeting, 2009.

Ferleger, D. The Evolution of Disability Rights Litigation (and some stories). http://mn.gov/mnddc/disability-litigation/right-to-treatment.html. Accessed Mar. 7, 2019.

French, S., and J. Swain. Working with Disabled People in Policy and Practice. Palgrave Macmillan, New York City, 2012.

Gardner, J., M. Chapman, G. Donaldson, and S. Jacobson. Toward Supported Employment. P.H. Brookes Pub. Co., Baltimore, 1988.

Greenfield, J. Check Out Recommendations from Lori's Transportation Transition Committee. Streetsblog.com, April 23, 2019.

Human Services Research Institute (2019). In Person Survey, 2018-2019 Final Report. National Association of State Directors of Developmental Disability Services, Cambridge, MA, 2019, pp. $159-169$.

Human Services Research Institute (2012). Working in the community: The status and outcomes of people with intellectual and developmental disabilities in integrated employment. NCI Data Brief, October 2012. Cambridge, MA: Human Services Research Institute.

Iezzoni, L., and B. O'Day. More than Ramps. Oxford University Press, Oxford [u.a.], 2006.

Larkin, M. Vulnerable Groups in Health and Social Care. Sage Publications, Thousand Oaks, CA, 2009.

Levinson, J. Making Life Work. University Press, Minneapolis, 2010.

Lindeke, B. Map Monday: Twin Cities Job Accessibility, Transit vs. Driving. https://streets.mn/2019/06/10/map-monday-twin-cities-job-accessibility-transit-vs-driving/. Accessed Jun. 11, 2019.

Meyer, L., C. Peck, and L. Brown. Critical Issues in the Lives of People with Severe Disabilities. P.H. Brookes Pub. Co., Baltimore, 1991. 
Mitchell, D., and V. Karr. Crises, Conflict and Disability. New York City, 2014.

Newcomer, E., and O. Zaleski. Lyft files for IPO: It touts its growth and reveals it lost \$991 million last year. Los Angeles Times, March 1, 2019.

Pedlar, A. A Textured Life. Wilfrid Laurier University Press, Waterloo, Ont., 1999.

Pratt, D. People with disabilities can spend months, years looking for work in Washington's smaller communities. Seattle Times, December 31, 2016.

Rees, R. Divvying up transportation dollars. Bend Bulletin, January 30, 2013.

Ringenbach, S., A. Albert, C. Chen, and J. Alberts. Acute Bouts of Assisted Cycling Improves Cognitive and Upper Extremity Movement Functions in Adolescents with Down Syndrome. Intellectual and Developmental Disabilities, Vol. 52, No. 2, 2014, pp. 124-135.

Rubenstein, D. In new suit, Uber, Lyft and Via target New York's wheelchair-accessibility requirements. Politico, April 13, 2018.

Russell, M. Beyond Ramps. Common Courage Press, Monroe, Me., 1998.

Sailor, C. Half a Century of helping kids become independent. Tacoma News Tribune, April 20, 2016.

Santos, A., N. McGuckin, H. Nakamoto, D. Gray, and S. Liss. Summary of Travel Trends; 2009 National Household Travel Survey. US Department of Transportation - Federal Highway Administration, Washington, D.C., 2011.

Scully, J. Disability Bioethics. Rowman \& Littlefield, Lanham, MD, 2008.

Serres, C., and G. Howatt. A Matter of Dignity. Minneapolis Star Tribune, November 8, 2015.

Staff, Mainebiz. \$70K grant to increase transportation options for seniors, disabled and lowincome residents. Mainebiz.biz, April 2, 2019.

Tozer, T. Redefining Disability. https://www.youtube.com/watch?v=OlHYUVKe-Y4. 2017. Accessed Apr. 17, 2019.

Vaughn, J. Disabled Rights. Georgetown University Press, Washington, D.C., 2003.

Wasfi, R, D. Levinson and A. El-Geneidy. Measuring the Transportation Needs of People with Developmental Disabilities. 2006.

Washington Department of Community Development. The Local Government Need and Demand Study on Zoning for Residential Care Facilities. Washington State, 1991.

Weisgerber, R. Quality of Life for Persons with Disabilities. Aspen Publishers, Palo Alto, CA, 1991. 
Wolbring, G. Expanding Ableism: Taking down the Ghettoization of Impact of Disability Studies Scholars. Societies, Vol. 2, No. 3, 2012, pp. 75-83.

Zachariah, H. Developmentally disabled share concerns with lawmakers, aides. Columbus Dispatch, April 5, 2019. 


\subsection{APPENDIX A}

The following is a physical representation of the electronic survey which was sent to respondents. While all of the questions are present skip logic is not possible to properly display. A page break signifies the end of a electronic page which was displayed on screen, therefore the next button would have to be clicked at those times. Additionally, the sliders used are not well represented in this format.

\subsection{Physical Survey}

Hello!

This survey is part of a study to determine how people with developmental and intellectual disabilities access transportation in the Portland (OR) area. Information on how this data will be used, your rights/privacy, and further discussion of this study are below.

This page, and the next 2 pages are intended to inform you about the research, about being a participant, and about your rights as a participant.

\begin{tabular}{ll}
\hline Project Title: & Travel Behaviors of People with Intellectual Disabilities \\
Researcher: & Joseph Totten, Civil and Environmental Engineering \\
& Portland State University
\end{tabular}

Researcher Contact: jtotten@pdx.edu / 651-895-3127

You are being asked to take part in a research study. The box below shows the main facts you need to know about this research for you to think about when making a decision about if you want to join in. Carefully look over the information in this form and ask questions about anything you do not understand before you make your decision.

\section{Key Information for You to Consider}

Voluntary Consent. You are being asked to volunteer for a research study. It is up to you whether you choose to involve yourself or not. There is no penalty if you choose not to join in or decide to stop.

Purpose. The reasons for doing this research are to ensure engineers, planners and other decisionmakers have access to and can address mobility concerns for people with intellectual disabilities.

Duration. It is expected that your part will last around 30 minutes.

Procedures and Activities. You will be asked to respond to the survey attached on the following pages.

Risks. Some of the possible risks or discomforts of taking part in this study include recalling or imagining stressful situations related to daily transportation.

Benefits. There will be no direct benefit, but the researchers hope to gain an understanding of the barriers to transportation access for persons with disabilities by listening directly from persons with intellectual disabilities.

Options. Participation is voluntary and the only alternative is to not participate.

What happens to the information collected?

Information collected from you for this research will be used to create guidance for planners, engineers and decisionmakers, this information will be distributed through scientific channels such as journal articles 
and presentations. No identifiable information will be collected, nor will your participation be disclosed to anyone.

\section{How will I and my information be protected?}

We will take measures to protect your privacy including always using password protected machines and accounts to analyze the data, and we have minimized the amount of sensitive data which will be collected. Despite taking steps to protect your privacy, we can never fully guarantee that your privacy will be protected.

To protect all of your personal information, we will always use password protected machines and accounts to analyze the data, and we have minimized the amount of sensitive data which will be collected. Despite these precautions, we can never fully guarantee that all your study information will not be revealed.

\section{What if I want to stop being in this research?}

You do not have to take part in this study, but if you do, you may stop at any time. You have the right to choose not to join in any study activity or completely stop your participation at any point without penalty or loss of benefits you would otherwise get. Your decision whether or not to take part in research will not affect your relationship with the researchers or Portland State University.

Will it cost me money to take part in this research?

There is no cost to taking part in this research, beyond your time.

\section{Will I be paid for taking part in this research?}

There is no payment associated with participation.

\section{Who can answer my questions about this research?}

If you have questions or concerns, contact the research team at:

Joseph Totten

651-895-3127

jtotten@pdx.edu

\section{Who can I speak to about my rights as a research participant?}

The Portland State University Institutional Review Board ("IRB") is overseeing this research. The IRB is a group of people who review research studies to make sure the rights and welfare of the people who take part in research are protected. The Office of Research Integrity is the office at Portland State University that supports the IRB. If you have questions about your rights, or wish to speak with someone other than the research team, you may contact:

Office of Research Integrity

PO Box 751

Portland, OR 97207-0751

Phone: (503) 725-5484

Toll Free: 1 (877) 480-4400

Email: hsrrc@pdx.edu

\section{Consent Statement}

I have had the chance to read and think about the information in this form. I have asked any questions I have, and I can make a decision about my participation. I understand that I can ask additional questions anytime while I take part in the research.

$\mathrm{X}$

Date

Assistant or guardian (if any)

$\mathrm{X}$

Date 


\section{INTRODUCTORY QUESTIONS}

These questions are meant to inform the research team how the data is being collected.

1) Is someone helping you with this survey?

Yes

No

1a) Who is helping you complete this survey?
A parent
A sibling
A friend
A neighbor
Other caretaker
Other family

2) Where do you live? Please provide a nearby intersection and the city you live in.

Please be as specific as you feel comfortable doing. These answers will allow us to consider how travel patterns differ throughout the region.

\section{TRAVEL DESTINATION AND MODE CHOICE}

These questions are intended to determine trip purposes and how (in general) people travel to these destinations

1) How often do you work or volunteer?
4-7 days a week
2-3 days a week
Once a week
Once every other week
Once a month
Never (if selected, skip to question 2)

1a) How do you usually get to work or to volunteer? (Select up to the 3 most frequent ways you travel to work or to volunteer)

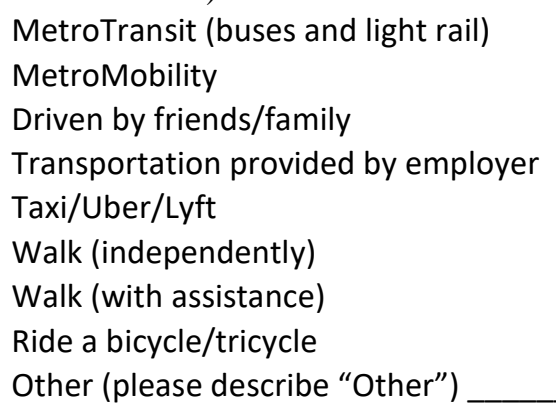

2) How often do you go to school or a day program?

4-7 days a week

2-3 days a week

Once a week

Once every other week

Once a month

Never (if selected, skip to question 3) 
2a) How do you usually get to school or a day program? (Select up to the 3 most frequent ways you travel to school or a day program)

- MetroTransit (buses and light rail)

MetroMobility

Driven by friends/family

$\square$ Transportation provided by school or day program

$\square$ Taxi/Uber/Lyft

$\square \quad$ Walk (independently)

Walk (with assistance)

Ride a bicycle/tricycle

$\checkmark$ Other (please describe "Other")

3) How often do you go shopping or run errands?

4-7 days a week

2-3 days a week

Once a week

Once every other week

Once a month

Never (if selected, skip to question 4)

3a) How do you usually get to stores for shopping or run errands? (Select up to the 3 most frequent ways you travel for shopping)

MetroTransit (buses and light rail)

MetroMobility

Driven by friends/family

Transportation provided by destination

Taxi/Uber/Lyft

Walk (independently)

Walk (with assistance)

Ride a bicycle/tricycle

Other (please describe "Other") 
4) How often do you go out for visiting friends or family, or having fun?

4-7 days a week

2-3 days a week

Once a week

Once every other week

Once a month

Never (if selected, skip to question 5)

4a) How do you usually get to visiting friends or family, or having fun? (Select up to the 3 most frequent ways you travel for these activities)
MetroTransit (buses and light rail)
MetroMobility
Driven by friends/family
Transportation provided by destination
Taxi/Uber/Lyft
Walk (independently)
Walk (with assistance)
Ride a bicycle/tricycle
Other (please describe "Other")

5) How often do you go to the doctor, or other medical services?
4-7 days a week
2-3 days a week
Once a week
Once every other week
Once a month
Never (if selected, skip to question 6)

5a) How do you usually get to the doctor or other medical services? (Select up to the 3 most frequent ways you travel for these activities)
MetroTransit (buses and light rail)
MetroMobility
Driven by friends/family
Transportation provided by destination
Taxi/Uber/Lyft
Walk (independently)
Walk (with assistance)
Ride a bicycle/tricycle
Other (please describe "Other") 
6) How often do you go to a restaurant?

$\square$ 4-7 days a week

$\square \quad$ 2-3 days a week

$\square \quad$ Once a week

$\square \quad$ Once every other week

$\square \quad$ Once a month

$\square \quad$ Never (if selected, skip to question 6)

6a) How do you usually get to a restaurant? (Select up to the 3 most frequent ways you travel for these activities)

$\square \quad$ MetroTransit (buses and light rail)

MetroMobility

Driven by friends/family

Transportation provided by destination

Taxi/Uber/Lyft

Walk (independently)

$\square \quad$ Walk (with assistance)

$\square \quad$ Ride a bicycle/tricycle

$\square$ Other (please describe "Other") 


\section{OPINIONS ON MODES}

These questions are meant to determine your opinions on different types of transportation and how those opinions affect your choices on how to travel

7) Do you use MetroMobility?

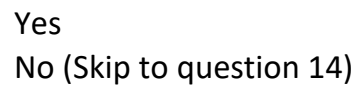

8) When riding MetroMobility how concerned are you about being the victim of a crime (circle your answer, with 1 being not at all concerned and 5 being very concerned)?

2

3

4

5

9) When riding MetroMobility how concerned are you about other vehicles and traffic safety (circle your answer, with 1 being not at all concerned and 5 being very concerned)?
1
2
3
4
5

10) When riding MetroMobility how concerned are you about being able to follow the rules of the service (circle your answer, with 1 being not at all concerned and 5 being very concerned)?

$\begin{array}{lllll}1 & 2 & 3 & 4 & 5\end{array}$

11) When riding MetroMobility how concerned are you about the speed of travel being too slow (circle your answer, with 1 being not at all concerned and 5 being very concerned)?

$\begin{array}{lllll}1 & 2 & 3 & 5 & 5\end{array}$

12) When riding MetroMobility how concerned are you about getting lost (circle your answer, with 1 being not at all concerned and 5 being very concerned)?
1
2
3
4
5

13) When riding MetroMobility how concerned are you about being alone (circle your answer, with 1 being not at all concerned and 5 being very concerned)?

2

3

4

5

14) Have you taken a transit rider training course?

Yes

No 
15) Do you use MetroTransit (buses and light rail)?

Yes

No (Skip to question 22)

16) When riding MetroTransit how concerned are you about being the victim of a crime (circle your answer, with 1 being not at all concerned and 5 being very concerned)?
1
2
3
4
5

17) When riding MetroTransit how concerned are you about other vehicles and traffic safety (circle your answer, with 1 being not at all concerned and 5 being very concerned)?

$\begin{array}{llll}1 & 2 & 3 & 5\end{array}$

18) When riding MetroTransit how concerned are you about being able to follow the rules of the service (circle your answer, with 1 being not at all concerned and 5 being very concerned)?

1

2

3

4

5

19) When riding MetroTransit how concerned are you about the speed of travel being too slow (circle your answer, with 1 being not at all concerned and 5 being very concerned)?
1
2
3
4
5

20) When riding MetroTransit how concerned are you about getting lost (circle your answer, with 1 being not at all concerned and 5 being very concerned)?

123

4 5

21) When riding MetroTransit how concerned are you about being alone (circle your answer, with 1 being not at all concerned and 5 being very concerned)? 
22) Have you taken a bicycle or tricycle riding training course?

$$
\begin{aligned}
& \text { Yes } \\
& \text { No }
\end{aligned}
$$

23) Are you able to ride a bicycle or tricycle independently?

$$
\begin{aligned}
& \text { Yes } \\
& \text { No }
\end{aligned}
$$

24) Do you ever ride a bicycle or tricycle?

$$
\begin{aligned}
& \text { Yes (if no skip to question 32) } \\
& \text { No }
\end{aligned}
$$

25) Do you ride a bicycle or tricycle for transportation or enjoyment?

$$
\begin{aligned}
& \text { Yes, transportation only } \\
& \text { Yes, enjoyment only } \\
& \text { Yes, both for transportation and enjoyment } \\
& \text { No, I do not cycle }
\end{aligned}
$$

26) When bicycling how concerned are you about being the victim of a crime (circle your answer, with 1 being not at all concerned and 5 being very concerned)?
1
2
3
4
5

27) When bicycling how concerned are you about other vehicles and traffic safety (circle your answer, with 1 being not at all concerned and 5 being very concerned)?

$\begin{array}{lllll}1 & 2 & 3 & 4 & 5\end{array}$

28) When bicycling how concerned are you about being able to follow the rules of the service (circle your answer, with 1 being not at all concerned and 5 being very concerned)?
1
2
3
4
5

29) When bicycling how concerned are you about the speed of travel being too slow (circle your answer, with 1 being not at all concerned and 5 being very concerned)?
1
2
3
4
5

30) When bicycling how concerned are you about getting lost (circle your answer, with 1 being not at all concerned and 5 being very concerned)?
1
2
3
4
5

31) When bicycling how concerned are you about being alone (circle your answer, with 1 being not at all concerned and 5 being very concerned)?
1
2
3
4
5 
32) Do you walk either for transportation or enjoyment?
Yes, transportation only
Yes, enjoyment only
- Yes, both for transportation and enjoyment
$\square \quad$ No, I do not walk (skip to question 39)

33) When walking how concerned are you about being the victim of a crime (circle your answer, with 1 being not at all concerned and 5 being very concerned)?

$\begin{array}{lllll}1 & 2 & 3 & 4 & 5\end{array}$

34) When walking how concerned are you about other vehicles and traffic safety (circle your answer, with 1 being not at all concerned and 5 being very concerned)?
1
2
3
45

35) When walking how concerned are you about being able to follow the rules of the service (circle your answer, with 1 being not at all concerned and 5 being very concerned)?
1
2
3
4
5

36) When walking how concerned are you about the speed of travel being too slow (circle your answer, with 1 being not at all concerned and 5 being very concerned)?
1
2
3
4
5

37) When walking how concerned are you about getting lost (circle your answer, with 1 being not at all concerned and 5 being very concerned)?
1 2 3
4
5

38) When walking how concerned are you about being alone (circle your answer, with 1 being not at all concerned and 5 being very concerned)?

1 


\section{STATEMENTS OF ABILITY}

This section asks about your abilities related to transportation. This section will help us determine how/if different skills are related to transportation independence.

39) I can travel independently (1-5 with 1 being unable to travel by yourself and 5 being able to travel independently for all travel)

12

2

3

4

5

40) I choose how I want to reach my destinations (1-5 with 1 being no choice in how to travel and 5 being full choice in how to travel) 2

3

4

5

41) I can read a map (1-5 with 1 being unable to read a map and 5 being fully understanding of maps)

1

2

3

4

5

42) I enjoy walking (1-5 with 1 representing a strong dislike of walking and 5 representing a strong enjoyment of walking)
1
2
3
4
5

43) More sidewalks and enhanced crosswalks would increase my independence (1-5 with 1 being more sidewalks and enhanced crosswalks would not increase my independence and 5 being more sidewalks and enhanced crosswalks would greatly increase my independence)
1
2
3
4
5

44) Are you able to ride a bicycle or tricycle independently?

a. Yes (skip to question 46)

b. No

45) Knowing how to ride a bicycle would increase my independence (1-5 with 1 being knowing how to ride a bicycle would not increase my independence and 5 being knowing how to ride a bicycle would greatly increase my independence)
1
2
3
4
5
Skip to Question 48

46) I enjoy riding a bicycle (if you can ride a bicycle, 1-5 with 1 representing a strong dislike of bicycle riding and 5 representing a strong enjoyment of bicycle riding)

1

2

3

4

5

47) More safe bike routes would increase my independence (1-5 with 1 being more safe bike routes would not increase my independence and 5 being more safe bike routes would greatly increase my independence) 


\section{DEMOGRAPHICS}

These questions aere about demographics, answering these questions will help make sure we have a representative sample of responses

48) Do you have a driver's license

$\square \quad$ Yes

Not currently, but in the past

$\square \quad$ No

49) How old are you?

$18-25$ years old

26-30 years old

31-35 years old

36-40 years old

41-45 years old

46-50 years old

51-55 years old

56-60 years old

$61+$ years old

50) What is your gender?

Male

$\square \quad$ Female

$\square \quad$ Other

51) What is your annual household income

Less than $\$ 10,000$

$\$ 10,000-\$ 14,999$

$\$ 15,000-\$ 24,999$

$\$ 25,000-\$ 34,999$

$\$ 35,000-\$ 49,999$

$\$ 50,000-\$ 74,999$

$\$ 75,000-\$ 99,999$

$\$ 100,000-\$ 149,999$

$\$ 150,000-\$ 199,999$

More than $\$ 200,000$ 
52) Do you live in a...

Private home or Condo

$\square$ Group facility

What kind of group facility (i.e. group home, nursing home, assisted living, etc.)

\section{Apartment}

$\square \quad$ Other (Please define)

53) Do you live with...

Relatives

Non-Relatives

Both Relatives and Non-Relatives

I live alone (skip to question 55)

Other (Please define)

54) How many people live in your household?

55) Do your consider yourself to be... (check all that apply)
a. White
b. Black or African American
c. American Indian or Alaska Native
d. Asian
e. Native Hawaiian or Pacific Islander
f. Hispanic or Latino
g. Other (Please define)

56) Do you have a medical condition or disability?

a. Yes

b. No (skip to question 58)

57) What is/are your medical condition or disability? 
58) Do you have any other comments, concerns or notes you would like to let us know about your transportation needs, choices and abilities?

Thank you for your participation

This completes the survey, thank you for your time and responses!

If you have any questions, or wish to follow-up to this survey, please email Joe Totten (jtotten@pdx.edu) 